\title{
Present Velocity Field in the Italian Region by GPS Data: Geodynamic/Tectonic Implications
}

\author{
Enzo Mantovani ${ }^{1}$, Marcello Viti ${ }^{1}$, Nicola Cenni ${ }^{2}$, Daniele Babbucci ${ }^{1}$, Caterina Tamburelli ${ }^{1}$ \\ ${ }^{1}$ Dipartimento di Scienze Fisiche, della Terra e dell'Ambiente, Università degli Studi di Siena, Siena, Italy \\ ${ }^{2}$ Dipartimento di Fisica ed Astronomia, Università degli Studi di Bologna, Bologna, Italy \\ Email: marcello.viti@unisi.it
}

Received 18 November 2015; accepted 26 December 2015; published 29 December 2015

Copyright (C) 2015 by authors and Scientific Research Publishing Inc.

This work is licensed under the Creative Commons Attribution International License (CC BY). http://creativecommons.org/licenses/by/4.0/

(c) (i) Open Access

\begin{abstract}
The analysis of geodetic observations carried out by 478 continuous GPS stations in the Italian region since 2001 has allowed a fairly good definition of the ongoing horizontal velocity field with respect to Eurasia. It is argued that such evidence can provide important insights into the geodynamic context in the central Mediterranean area. Numerous velocity vectors in the Apulia zone coherently indicate that the southern Adriatic domain is moving roughly NE ward. Since no significant decoupling zone between this domain and Nubia has so far been recognized, one could expect that the kinematics of these two plates is compatible. However, this condition is not fulfilled if the Nubia-Eurasia relative motion is taken from the global kinematic models, either deduced by long-term evidence [1] or short-term geodetic data [2] [3]. This problem is considerably reduced if the alternative Nubia-Eurasia rotation pole suggested by [4] is taken into account. This choice is also suggested by other major long-term evidence in the Mediterranean region. The numerous geodetic vectors available in two Adriatic sectors, the Apulia zone and the Venetian plain, would imply an Adria-Eurasia rotation pole incompatible with all Nubia-Eurasia Eulerian poles so far proposed. Since a significant relative motion between these plates is not compatible with the absence of a tectonic decoupling zone, we suppose that the short-term kinematics of Adria might be influenced by a transient non-rigid behaviour of that plate. This hypothesis is compatible with the expected effects (post seismic relaxation) of the major decoupling earthquakes that have occurred along Periadriatic zones in the past tens of years. The compatibility of the GPS kinematic pattern in the Apennine belt, Calabria Arc and Sicily with the implications of the geodynamic/tectonic interpretations so far proposed for the central Mediterranean area is then discussed.
\end{abstract}

\section{Keywords}

Geodesy, Geodynamics, Italy, Central Mediterranean

How to cite this paper: Mantovani, E., Viti, M., Cenni, N., Babbucci, D. and Tamburelli, C. (2015) Present Velocity Field in the Italian Region by GPS Data: Geodynamic/Tectonic Implications. International Journal of Geosciences, 6, $1285-1316$. http://dx.doi.org/10.4236/ijg.2015.612103 


\section{Introduction}

It is widely recognized that the evolution of the Mediterranean area has been considerably influenced by the convergence between Africa and Eurasia. However, the fact that major extensional processes, such as the formation of relatively large back-arcbasins, have developed in the Mediterranean region during its Neogene evolution has led some authors to suppose that the convergence of the surrounding plates is not the unique driving mechanism. In particular, it has been suggested that the gravitational sinking of subducted lithosphere (slab roll-back) has considerably contributed to the above processes [5]-[7]. This last hypothesis has been confuted by some authors [8]-[14], who suggest that the Neogene deformation pattern in that area can plausibly and coherently be explained as an effect of the motion of Nubia (sensu [1]) and the Anatolian-Aegean-Balkan system with respect to Eurasia.

The spreading of opinions about the geodynamic setting in the Mediterranean region is significantly influenced by the fact that the relative motion between Nubia and Eurasia is not uniquely recognized yet. Uncertainty mainly concerns the trend of such plate convergence and the configuration and kinematics of the Adriatic plate. Global kinematic models based on the analysis of long-term evidence (late Pliocene-Quaternary North Atlantic mid-oceanic ridge spreading rates and transform fault azimuths, [1] [15] [16]) suggest that at Mediterranean latitudes Nubia moves roughly NW to NNW ward with respect to Eurasia. Global models inferred from shortterm space geodesy data [2] [3] provide a Nubia-Eurasia relative motion with direction more oriented towards the west [17].

However, as argued by [4], the above convergence trend can hardly be reconciled with several major features of the Quaternary deformation pattern in the whole Mediterranean region, which rather suggests a NNE ward orientation of such plate convergence.

To explain why the Nubia-Eurasia pole provided by global kinematic models may be not reliable, [4] point out that the plate configuration adopted by such analyses is oversimplified, since it involves a two plates model (Nubia and Eurasia), notwithstanding that the distribution of seismic and tectonic features in the interposed regions suggests the presence of two independent microplates (Morocco and Iberia). This possibility is particularly interesting since the NNE ward trend of the Nubia-Eurasia relative motion suggested by Mediterranean constraints can be also reconciled, within errors, with the North Atlantic kinematic constraints, if the proposed four plates configuration (Figure 1) is taken into account [4].

In this work, we point out some aspects of the space geodetic (GPS) velocity field in the Italian area that can provide significant constraints on the Nubia-Eurasia relative motion, and the kinematics of other important structures in the central Mediterranean area, such as the Adriatic plate (Adria), the Apennine belt and the Calabrian and Hyblean wedges.

\section{GPS Network and Data Processing}

The space geodetic (GPS) observations obtained from 478 continuous stations operating in the Italian area and surroundings over the period January 1, 2001 April 30, 2015 have been considered in order to estimate the present horizontal kinematic field.

The phase and pseudo-code data for each station have been analyzed by the GAMIT software version 10.5 [18] adopting a distributed procedure [19], as described by [20] [21]. The whole network has been divided into 43 clusters, following a simple geographic criterion, while maintaining the shortest baseline as possible. Loose constraints $(100 \mathrm{~m})$ have been assigned to the daily position coordinates of each station belonging to all clusters. The International GPS service for Geodynamics (IGS) precise orbital solutions from Scripps Orbit and Permanent Array Center have been included in the processing with tight constraints, such as the Earth Orientation Parameter. The daily loosely constrained solutions have been combined into a unique solution by the GLOBK software [22], and aligned into the ITRF2008 reference frame [3] by a weighted six parameters transformation (three translations and three rotations), using the ITRF2008 coordinates and velocities of the 13 high-quality common IGS stations shown in the inset of Figure 2.

Then, the time series have been analyzed to estimate the north, east and vertical components of the geographical position of each site, following the procedure described by [20] [21]. Only the sites with a minimum length of 2.5 years have been included in the processing in order to avoid biases generated by unreliable estimated seasonal signals [23] and/or by rate uncertainties, due to short time series [24]. As argued in several papers [24]-[28], the noise in time series can be described as a power law process. 


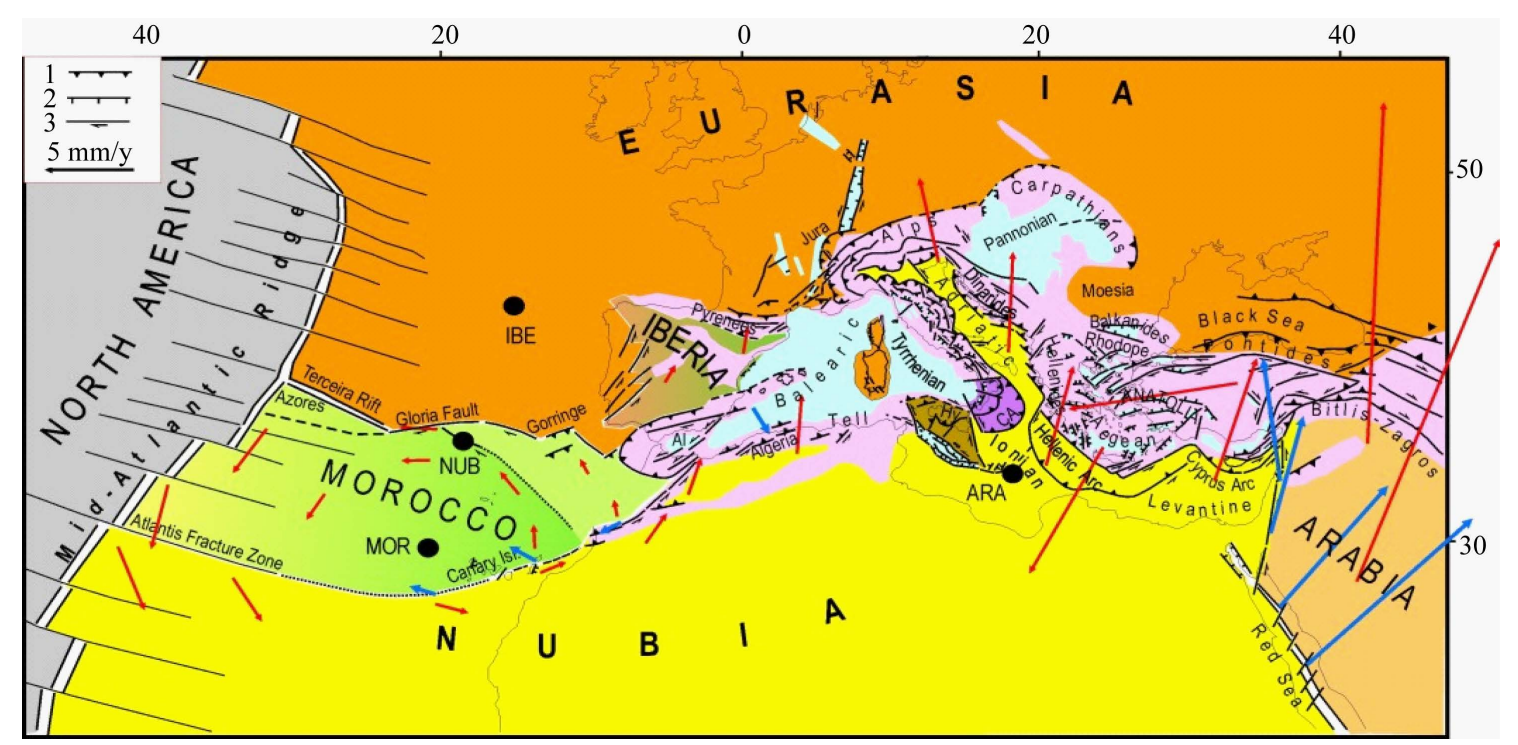

Figure 1. Plate configuration and long-term (Quaternary) kinematic pattern in the Mediterranean region provided by [4]. Black dots identify the location of the proposed Euler poles of the Arabia (ARA), Iberia (IBE), Morocco (MOR) and Nubia (NUB) plates with respect to Eurasia. Red arrows indicate the motions of the above plates with respect to Eurasia predicted by the respective Euler poles and the motion of the Anatolian-Aegean system. Blue arrows along plate borders show the relative motion of the Morocco and Arabia plates with respect to Nubia. CA = Calabrian wedge (violet), Hy = Hyblean wedge (brown). The velocity field shown in the Anatolian-Aegean system is compatible with geological evidence (see [8][10] [14]). See [4] for details about the configuration and kinematics proposed for the easternmost part of the Morocco plate (light green). Main orogenic belts are pink. 1, 2, 3: Compressional, extensional and transcurrent features.

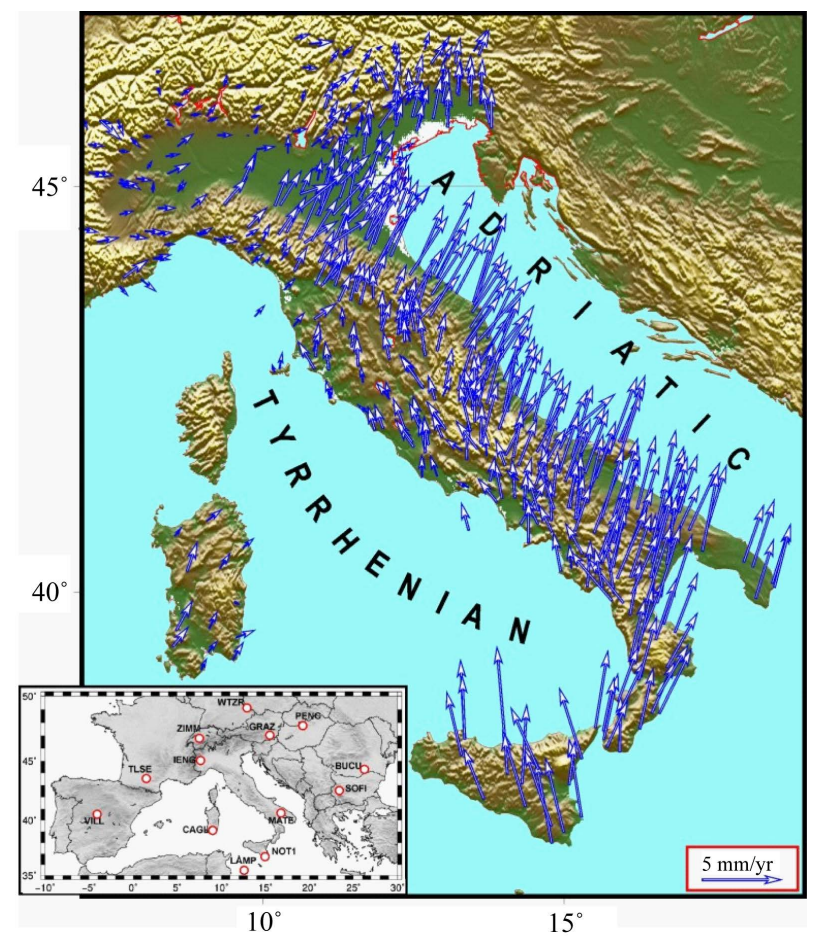

Figure 2. Horizontal velocities (blue vectors) of the GPS sites with respect to a fixed Eurasian frame (Euler pole at $54.23^{\circ} \mathrm{N}, 98.83^{\circ} \mathrm{W}, \omega=$ $0.257^{\circ} / \mathrm{Myr}$ [3]). The inset shows the location of the 13 IGS stations that have been used to align the daily solutions of the network to the ITRF 2008 references frame [3]. 
Different methods have been developed to characterize noise in GPS time series and its impact on velocity uncertainties [26] [27] [29] [30]. We have used the reformulated computation method of the Maximum Likelihood Estimation introduced by [30] in order to estimate the characteristics of the noise and the realist uncertainties associated with velocity values. The resulting ITRF2008 horizontal velocity vectors with respect to the adopted Eurasian frame [3] are reported in the Appendix and mapped in Figure 2.

\section{Possible Tectonic Implications of the Geodetic Velocity Field}

\subsection{Southern Adria Kinematics and Nubia-Eurasia Relative Motion}

The velocity field shown in Figure 2 clearly indicates that the Apulia zone (Southeastern Italy), certainly belonging to the southern Adriatic domain [31] [32], is moving roughly NE ward, with a rate of about 4 - 5 $\mathrm{mm} /$ year. This evidence is fairly robust since it is coherently indicated by more than 20 velocity vectors and is consistent with the indications provided by the analysis of earthquake focal mechanisms in Periadriatic zones [33]-[35]. If Nubia were moving roughly NNW to NW ward, as predicted by global kinematic models, it would be necessary to identify an active decoupling zone between Nubia and Adria.

Attempts at identifying such decoupling have been made by several authors [33] [35]-[44]. However, the considerable spreading of the solutions so far proposed (Figure 3), concerning location, trend and tectonic nature of the presumed decoupling zones, clearly underlines the ambiguity of the available evidence, as pointed out by

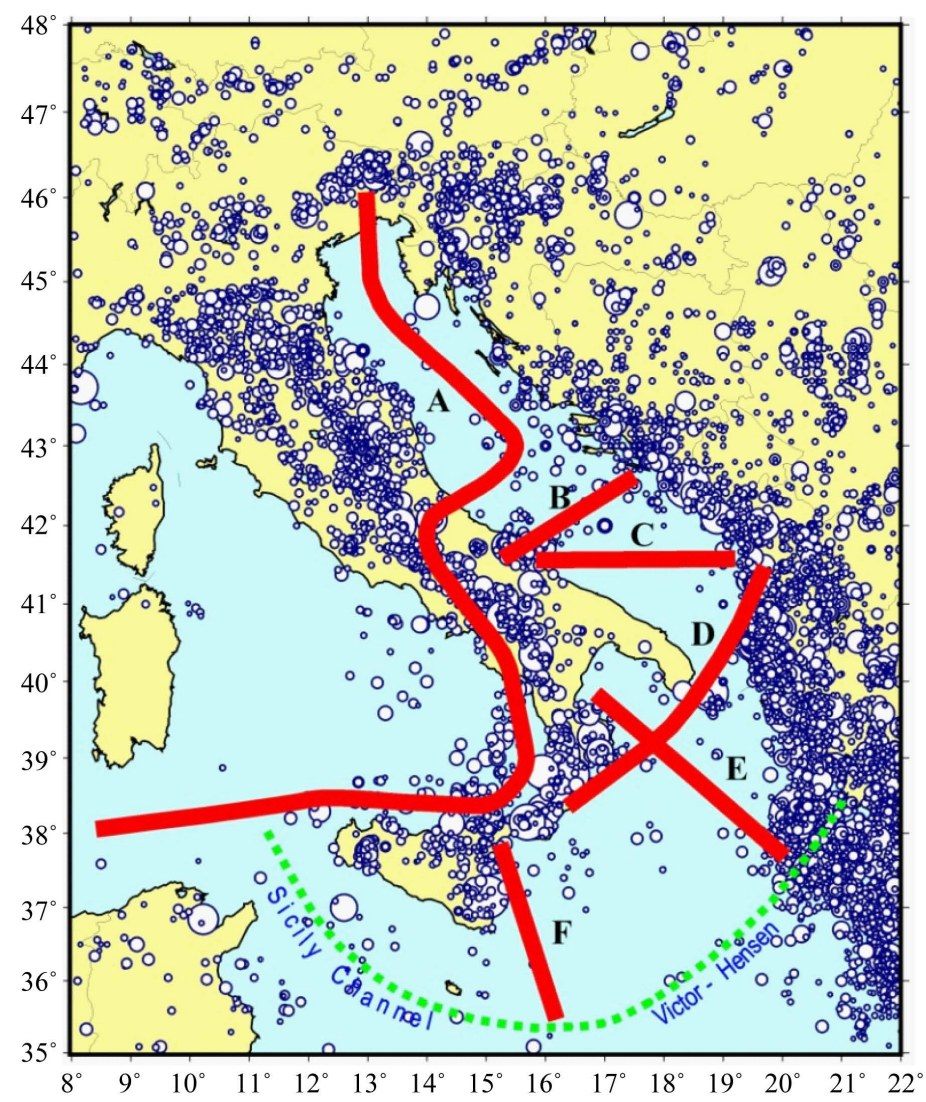

Figure 3. Distribution of major seismicity $(M \geq 5.0)$ in the Adriatic domain and surroundings from 1600 [48] [49] and configuration of the decoupling zones between the Adria and Nubia domains proposed by a) [40]; b) [35] [36] [44]; c) [37] [38]; d) [33]; e) [41] [43]; f) [39]. The dotted green line indicates the fault systems (Sicily Channel and Victor Hensen) that, following [10], have decoupled the Adriatic-Ionian plate from Nubia since the Late Miocene (with a considerable slowdown of the relative motion since the middle Pleistocene). 
some authors [17] [45] [46]. The most significant evidence about the lack of a clearly recognizable decoupling zone between Nubia and Adria is given by the low level of seismicity in the presumed decoupling zones (Figure 3) and by the fact that none of them correspond to a major active fault system cutting through the Adria domain [46] [47].

The major difficulty pointed out above cannot simply be ignored. Since the kinematics of southern Adria seems to be well defined, one should carefully check the reliability of the Nubia-Eurasia relative motion provided by global kinematic models [1]-[3]. As argued earlier, a detailed discussion about this problem is given by [4] [14], who have proposed an alternative hypothesis about the Nubia-Eurasia convergence (Figure 1). This solution should seriously be taken into account since does not involves any major difficulty. First of all, the proposed Nubia-Eurasia relative motion is compatible with southern Adria's geodetic field, and thus does not require the frustrating search of an unlikely decoupling zone. Furthermore, such kinematic model can be reconciled with major Mediterranean and North Atlantic kinematic constraints, as described by [4].

The above kinematic solution has been criticized by [2], who do not recognize the Iberia and Morocco independent microplates hypothesized by [4]. As concerns Iberia, [2] postulate that no significant relative motion between that domain and Eurasia is taking place at the Pyrenean collision zone, in particular the $1.5 \mathrm{~mm} / \mathrm{y}$ convergence rate implied by the [4] model. However, it is difficult to believe that such small relative motion can be ruled out for a boundary zone where significant seismic activity takes place (Figure 4), and several compressional and traspressional active faults have been identified (e.g., [50] [51]). For instance, [50] estimate that in the western Pyrenees the roughly E-W Lourdes thrust alone may accommodate up to $0.25 \mathrm{~mm} / \mathrm{yr}$ of N-S convergence. So, it can hardly be excluded that seismic and/or aseismic fault slip at the whole Pyrenean tectonic boundary may accommodate the above mentioned convergence rate.

[2] also suggest that seismotectonic activity in western Iberia could not account for the Iberia-Eurasia relative motion predicted by [4]. However, recent works [52] confirm that such zone is dissected by a number of active NNE-striking faults, whose slip rates could reach $0.8 \mathrm{~mm} / \mathrm{yr}$, which roughly matches the amplitude of the Iberia-Eurasia relative motion predicted by [4]. In our opinion, the fact that both the boundary zones between the presumed Iberia plate and Eurasia are affected by significant seismicity (Figure 4) cannot easily be reconciled with a null relative motion between such plates. Another problem raised by [2] is the fact that some predictions of the [4] model are not compatible with the geodetic velocities of 3 geodetic sites in Iberia (Ebro, Madrid, Ybes, Figure 4). In this case as well, the difference between observed and predicted velocities is of the order of 1 $\mathrm{mm} / \mathrm{y}$, that may be compatible with the possible uncertainty of GPS data.

[2] also recall that magnetic lineations in the North Atlantic have been interpreted as an evidence that Iberia has moved as part of Eurasia in the last $10 \mathrm{My}$ [53]. However, one must be aware that spreading rates at the North Atlantic ridges are mainly influenced by the motion component of Atlantic domains perpendicular to

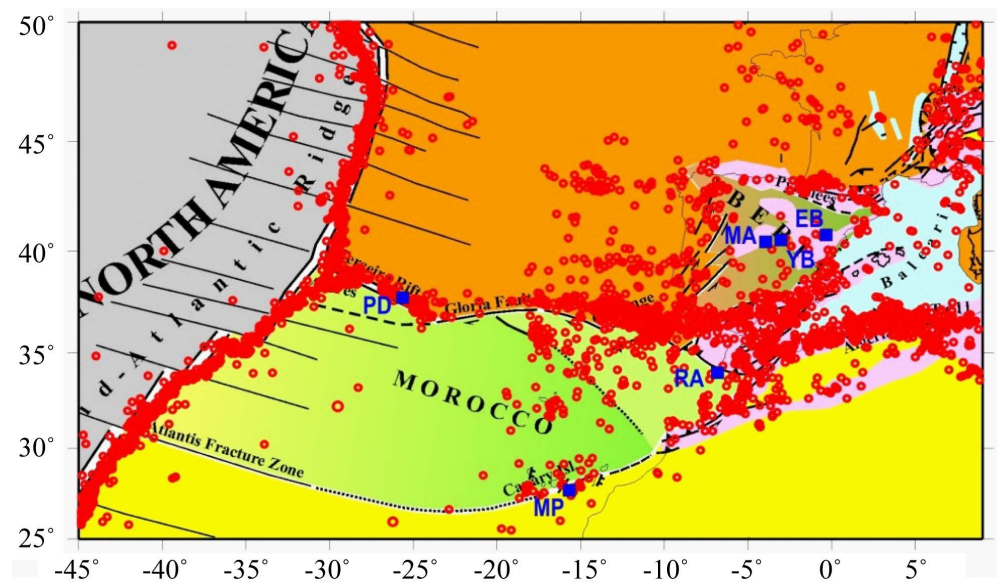

Figure 4. Seismicity distribution in the Western Mediterranean and central Atlantic region $(M \geq 4.0,1970-2015)$ from the database of the Incorporated Researcher Institutions for Seismology (IRIS), available at http://ds.iris.edu/ds/nodes/dmc/data//.EB, MA, YB, MP, PD, RA indicate the location of the Ebro, Madrid, Ybes, Mas Palomas, Ponta Delgada and Rabat GPS stations. 
ridges (mainly oriented E-W), and that consequently the presumed roughly N-S relative motion $(1.5 \mathrm{~mm} / \mathrm{y})$ between Eurasia and Iberia can hardly produce significant effects on spreading rates at those ridges.

Moreover, [13] suggest that the actual Iberia microplate considerably differs from the previous Atlantic-Iberia plate. Indeed, since the late Miocene the Iberia microplate decoupled from the oceanic sector located between the Mid Atlantic Ridge and the Portugal fault system, which became part of Eurasia [13].

As concerns the Morocco microplate, [2] point out a discrepancy between the predictions of the MoroccoNubia pole provided by [4] and the geodetic velocities at Mas Palomas (Figure 4). However, it must be considered that such site lies along an active tectonic boundary zone (as recognized by [2] and that consequently the real meaning of such observation cannot easily be recognized. [2] also suggest discrepancies between the predictions of the [4] Morocco-Eurasia pole and the geodetic velocities in the Ponta Delgada and Rabat sites (lying inside the presumed Morocco microplate). However, the entities of such discrepancies are compatible with the possible uncertainty of geodetic data.

[2] also remark that the strike-slip motion provided by [4] at the Atlantis-Canary Islands fracture zone (taken as the southern boundary of the presumed Morocco microplate) is not compatible with the lack of seismicity. However, it must be considered that the section of that fracture going through the Canary Islands has been affected by considerable tectonic, seismic and volcanic activity [54]. It is worth noting that [55] adopted the plate configuration suggested by [4], involving an independent Morocco microplate bounded by the Atlantis-Canary Islands fracture zone, to explain the magmatic processes that developed in the Canary Islands. As concerns the sector of that fracture zone lying west of the Canary Islands, one should consider that reliable information about seismic activity may only be available for the last tens of years. Anyway, it is worth noting that most of the current volcanic activity of the Canary Islands, often associated with earthquake swarms [56], occurs near the El Hierro island, which is the youngest volcanic complex of the archipelago, located at the eastern edge of the fracture zone envisaged by [4].

[57] point out that the results of statistical tests involving three GPS sites located in the Canary Islands (LPAL, GMAS and MAS1) confute the necessity of the independent Morocco microplate proposed by [4]. However, the same authors admit that the stations located in Morocco (RABT, IFRN and TETN) show residual velocities (with respect to the Nubia-Eurasia motion) exceeding $1 \mathrm{~mm} / \mathrm{y}$, suggesting that Morocco may not be rigidly coupled with Nubia.

To tentatively explain the difference between the Nubia-Eurasia kinematic models derived by geodetic data and geological evidence, [2] argue that the kinematics of the plate involved is changed in the short-term. However, this hypothesis may weaken the objections of such authors about the discrepancies they claim between the predictions of the [4] long-term kinematic model and some geodetic velocities.

As last, one could recall that the plate configuration of the first long term global kinematic model (NUVEL-1 [15]) is significantly different from the last one (MORVEL [2]), which involves a number of new microplates. In particular, recent works ([2] [57]) suggest that the Somalia and Lwandle microplates are probably independent from the former Africa plate, whereas the eastern boundary of the original Eurasian plate could be a complex mosaic formed by the Amur, Okhotsk, Yangtze and Sundaland microplates, along with other minor blocks. Such fragmentation of lithospheric domains, once believed to be very large coherent plates, may encourage the scientific community to make a more accurate check of the plate configuration proposed by [4].

\subsection{Adria Plate?}

The GPS velocity field shown in Figure 2 provides information about the present kinematics of two zones certainly belonging to the Adria continental domain (Figure 5). One is Apulia, as discussed in the previous point, and the other is the Venetian plain, i.e. the Adria foreland area which underthrusts the eastern Southern Alps [32]. This evidence is very significant since it is coherently indicated by a relatively high number (more than 20 in both zones) of subparallel velocity vectors.

If Adria were assumed to behave as a rigid independent plate, the two geodetic constraints mentioned above would imply an Adria-Eurasia rotation pole roughly located in the Western Alps. This result, compatible with the ones previously obtained by the analysis of earthquake slip vectors in Periadriatic zones [33] [35] [36], would mean that Adria does not move in close connection with Nubia, whatever Nubia-Eurasia pole is considered among the ones so far proposed. However, such conclusion can hardly be reconciled with the lack of a clear active decoupling zone between Adria and Nubia. Thus, we rather suppose that the short-term evidence (either 


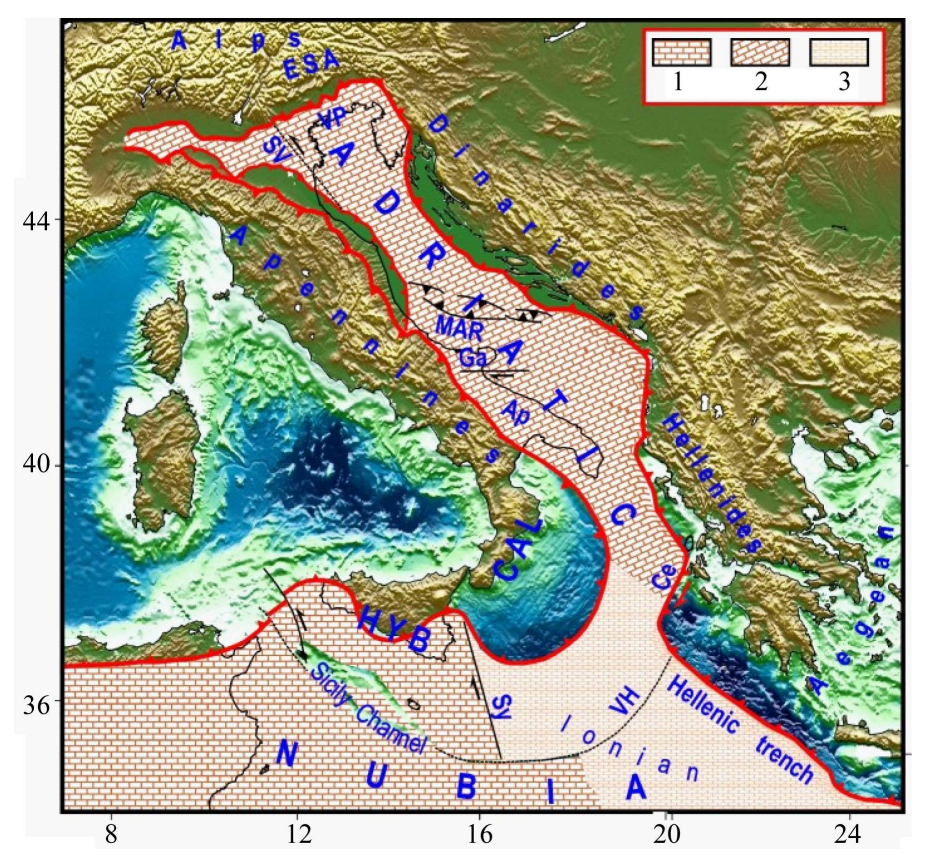

Figure 5. Sketch of major structural domains in the Central Mediterranean area. 1-2) African and Adriatic continental domains, 3) Oceanic Ionian domain, Other symbols as in Figure 1. A description of the previous tectonic phases that have led to the present configuration of the Adriatic plate and surrounding belts is given in Figure 5 and the related comments in the text. $\mathrm{AP}=$ Apulia, $\mathrm{CAL}=$ Calabrian wedge, $\mathrm{Ce}=$ Cefalonia fault system, $\mathrm{ESA}=$ Eastern Southern Alps, Ga = Gargano, $\mathrm{HYB}=$ Hyblean wedge, $\mathrm{MAR}=$ Mid Adriatic ridge, $\mathrm{SV}=$ Schio-Vicenza fault system, $\mathrm{Sy}=$ Siracusa fault system, $\mathrm{VH}=$ Victor Hensen fault system, VP = Venetian Plain.

geodetic data or/and earthquake slip vectors) refers to a transient non-rigid behaviour of the Adria domain. This effect may be due to the peculiar distribution of seismic decouplings that have occurred in the Periadriatic boundary zones during the last tens of years. For investigating this problem we have taken into account the evidence and arguments presented by [49] [58] [59], which suggest that major seismicity in the Periadriatic zones tends to undergo a progressive northward migration through the eastern (Dinarides) and western (Apennine) boundary zones, up to reach the northern front of the Adria plate (Eastern Southern Alps).

The analysis of the post 1400 seismic histories of the Periadriatic zones has allowed the above authors to recognize a number of migrating seismic sequences, each lasting about 200 years [49] [58]. The last presumably complete sequence has probably developed until about 1920-1930. In the successive sequence (still ongoing, Figure 6), major Periadriatic earthquakes have mainly occurred in the Southern and Central Apennines and in the Southern Dinarides-Albanides sector, while only few shocks have affected the Adriatic boundary zones located more to the North (Northern Apennines, Northern Dinarides and Eastern Southern Alps).

Considering this seismicity distribution and the post-seismic relaxation effects that such earthquakes have triggered in the Adria domain [60]-[63], one could suppose that the short-term kinematics of southern Adria may resemble the long-term behaviour, whereas the northern part of Adria, not yet decoupled from the surrounding structures, is moving with a lower rate respect to the long-term one [48] [59]. This differential displacement rate involves a roughly SE-NW compressional regime in the middle Adria zone. It is reasonable to suppose that such transient (or partially transient) shortening phase has systematically developed during the past migration phases of Adria [48] [59]. In the long-term, the total effect of the periodic SE-NW compressional pulses could have caused the formation of the Mid Adriatic Ridge (Figure 7(d)), an uplifted structure in the central Adriatic which has been evidenced by seismic surveys and interpreted as a consequence of longitudinal shortening in the Adriatic platform [34] [46] [47].

A number of authors, assuming a rigid behaviour of Adria, have used short-term evidence (geodetic and seismological data) to advance various hypotheses about the configuration and kinematic pattern of one or more 


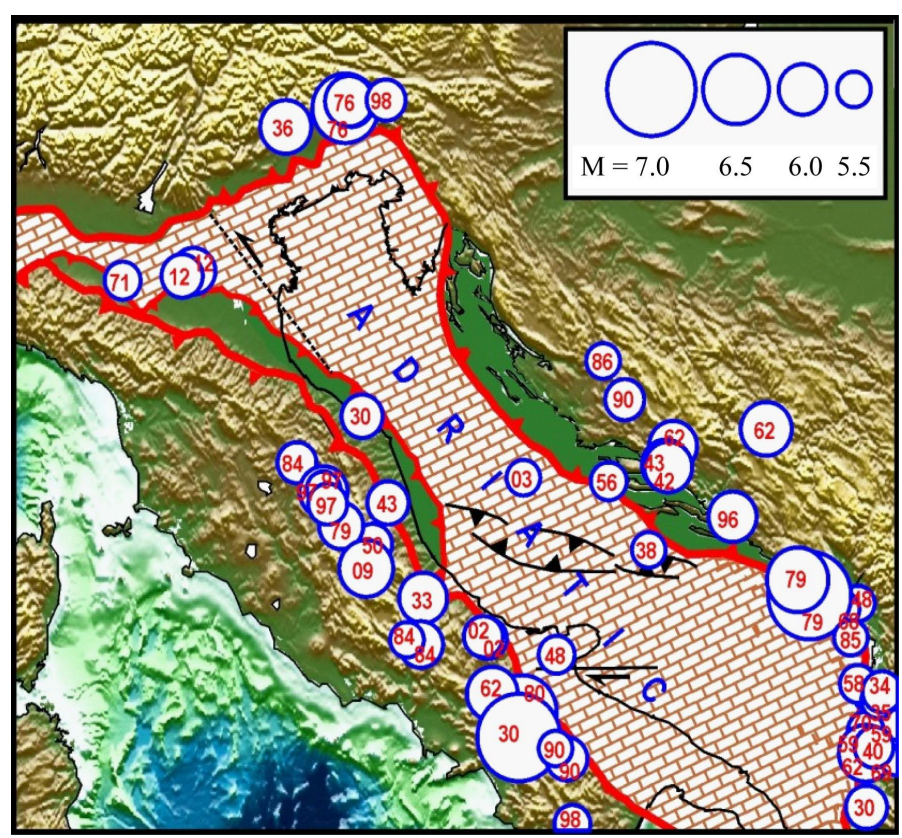

Figure 6. Major earthquakes occurred in the Periadriatic zones since 1930 [48] [49]. Each shock is supposed to allow the decoupling of the Adriatic plate from the surrounding structures.

Adria blocks [17] [35]-[44]. However, as discussed by [46], the expected tectonic implications of the proposed contexts have not properly been compared with the observed Quaternary deformations. In this regard, one should be aware that a reliable recognition of the ongoing plate configuration and kinematics in the study area can only be obtained by an integrated and accurate analysis of the spatio-temporal distribution of major tectonic events, aimed at recognizing the entire evolution of the study area. In fact, a reliable reconstruction of the whole story may impose important constraints on the present tectonic setting, which may considerably help to identify the most reliable interpretation. An attempt in this direction, carried out by [10] [11], taking into account a large amount of long-term data in the whole Mediterranean region, has suggested the evolutionary reconstruction shown in Figure 7.

The proposed evolution provides that the Adriatic promontory moved as a part of Africa until the Late Miocene (Figure 7(a)). Since that time, the direct contact between the continental Adriatic domain and the buoyant Balkan peninsula (moving roughly westward) caused a profound reorganization of the tectonic kinematic setting in the central Mediterranean area, conditioned by the need of activating less resisted E-W shortening processes (minimum action principle, [10] [11]). This reorganization involved the decoupling of the Adriatic-Ionian and Hyblean plates from Nubia (Figure 7(b)), through the activation of the Victor-Hensen and Sicily Channel strikeslip/transtensional fault systems. To accommodate the roughly E-W shortening between the Adria-Ionian plate and the Northwestern Nubia domain (Tunisia), the Hyblean wedge has undergone a roughly NW ward extrusion. On its turn, the indentation of this extruding wedge caused the lateral escape of wedges from the Apennine-Alpine belt (which at that time lain to the east of Sardinia), at the expense of the thinned continental Adriatic and the oceanic Ionian domains (Figure 7(b)). The decoupling of the Hyblean wedge from Nubia has been allowed by the activation of the Sicily Channel and the Syracuse fault systems, where post early Messinian deformation is recognized [64] [65].

As argued in detail by Mantovani et al. (2009, 2014), the above context can plausibly and coherently account for the complex spatio-temporal distribution of major tectonic events that almost simultaneously started in the Late Miocene and then developed until the upper Pliocene in the central Mediterranean area, such as the formation of the Sicily Channel tectonic zone and the Victor-Hensen fault system, the extensional activity in the central Tyrrhenian basin (Magnaghi-Vavilov), the orogenic pulse that involved the whole Apennine belt, the activation of a major strike-slip discontinuity in the northern Adriatic area (Schio-Vicenza fault system), the roughly northward displacement of the sector of the Maghrebian-Alpine belt which lied north of the Hyblean wedge and 


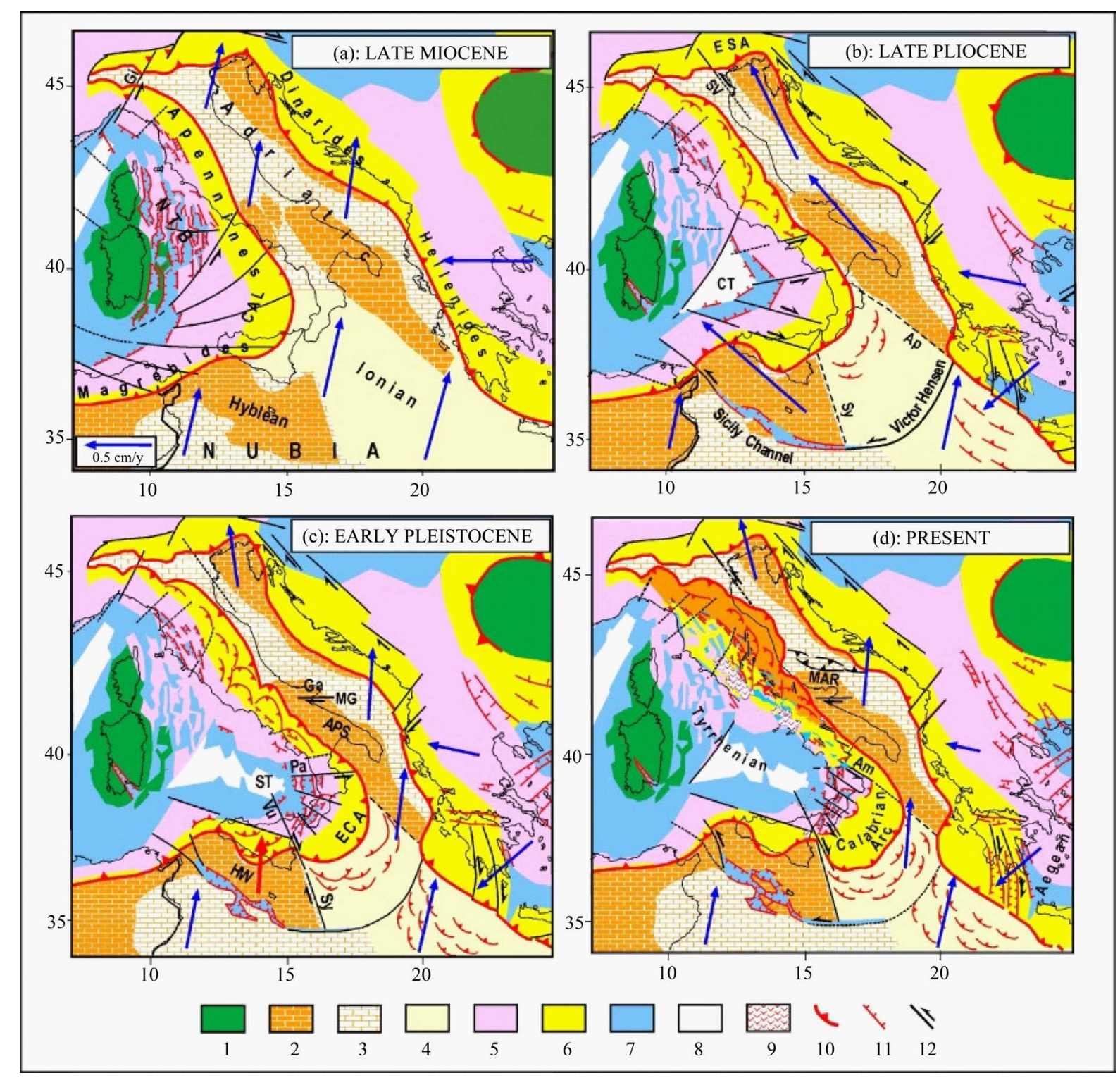

Figure 7. Evolutionary reconstruction of the central Mediterranean region proposed by [10] [11]. (a) Late Miocene. CAL = Calabria, Gi = Giudicarie fault system, NTB = Northern Tyrrhenian basin; (b) Late Pliocene. Ap = Apulian escarpment, CT = Central Tyrrhenian (Magnaghi and Vavilov basins), ESA = Eastern Southern Alps, SV = Schio-Vicenza fault system, Sy = Syracuse escarpment; (c) Early Pleistocene. APS = Apulian Swell, ECA = External Calabrian Arc, Ga = Gargano, HW = Hyblean wedge, MG = Mattinata-Gondola fault, $\mathrm{Pa}=$ Palinuro fault, ST = South Tyrrhenian, Sy = Syracuse fault system, $\mathrm{Vu}$ = Vulcano fault; (d) Present. Am = Amendolara ridge, MAR = Mid Adriatic Ridge.1) European continental domain; 2, 3) Africa-Adriatic continental and thinned continental domains; 4) Neotethys oceanic domain; 5) Alpine belt; 6) Neogenic accretionary belts; 7, 8) Neogenic extensional basins and oceanized zones; 9) Quaternary magmatism; 10, 11, 12) Major compressional, extensional and transcurrent tectonic features. Thin lines identify the present geographical contours. The paleoposition of the Tunisian coast (thick line) is reported for reference in the evolutionary maps. Blue arrows indicate plate motions with respect to Eurasia [10] [11] [14].

other tectonic events.

Since the late Pliocene (Figure 7(c)), due to the entering of thick Adriatic continental lithosphere at the Southern Apennines trench zones, lateral escape of buoyant orogenic wedges mainly developed in the Calabrian sector of the belt. This wedge, stressed by belt-parallel compression has undergone rapid uplift [66] [67] and lateral escape, at the expense of the adjacent Ionian oceanic domain. This process had major effects at both the inner side (opening of the southernmost Tyrrhenian basin, Marsili) and on the outer front (accretionary activity 
in the External Calabrian Arc) of the escaping Calabrian wedge. During extrusion, this wedge, laterally bounded by the Palinuro and Vulcano strike-slip guides, has also undergone strong fragmentation, with the formation of several transversal and belt parallel fault systems, in response to belt parallel compression.

During the same evolutionary stage, the southern Adria sector, contemporaneously stressed by the westward push of the Balkan peninsula and the roughly NNE ward push of Nubia (transmitted by the Calabrian Arc), has undergone upward flexure [68] [69]. The fact that only the southern portion of Adria was stressed by the westward push of the Anatolian-Aegean-Balkan system might have induced a dextral shear stress in the central part of that plate, in good correspondence to the Gargano zone, where the Mattinata fault system was reactivated with a dextral movementstill active [70]-[72].

Since the early Pleistocene (Figure 7(d)), the direct contact between the northern part of the Calabrian wedge and the thick continental Adria domain caused a significant slowdown of northern Calabria's outward escape, recognized by geological evidence [67], emphasizing the decoupling of the northern sector (slowed down) from the southern one (not slowed down). Furthermore, the orientation of the northern Calabrian escape changed from about ESE to SE ward, as suggested by the available evidence [65].

After the slowdown of northern Calabria, the Palinuro decoupling fault system became almost inactive. However, the outward escape of northern Calabria has not completely ceased, becausein the late Pleistocene the activation of a NW-SE transpressional tectonic zone (Amendolara ridge, Figure 7(d) [73]) offshore northern Calabria has allowed such block to maintain some movement towards the Ionian oceanic domain. This extrusion, accompanied by a counterclockwise rotation, could be responsible for the post Middle Pleistocene extensional regime that has occurred in the Crati trough in northern Calabria [67] [74].

Since the late Pleistocene (Figure 7(d)), the relative motion of the Adria-Ionian plate with respect to Nubia has undergone a considerable slowdown, due to the increasing resistance to shortening along the surrounding buoyant orogenic structures (Hellenides, Dinarides, Alps and Apennines). This trend suggests that at present the motion of Nubia cannot be significantly different from that of southern Adria.

The proposed reconstruction provides that since the middle Pleistocene the outer sector of the Apennine belt, stressed by Adria, has undergone belt parallel shortening, which has been accommodated by outward extrusion and uplift, as shown with a greater detail in Figure 8. The outer mobile portion of the Apennine belt is formed by the Molise-Sannio (MS) wedge in the Southern Apennines, the eastern sector of the Lazio-Abruzzi carbonate platform (ELA) in the Central Apennines, and the Romagna-Marche-Umbria (RMU) and Toscana-Emilia (TE) wedges in the Northern Apennines. The separation of the outer mobile wedges from the inner (Tyrrhenian) sector of the belt has been accommodated by the generation of a series of troughs. The escaping material only includes the sedimentary cover, decoupled from its crustal basement at seismogenic depth (of the order of $6-10$ $\mathrm{km}$ ) by mechanically weak lithological horizons, as evidenced by seismic surveys [75]. In particular, a Late Triassic evaporitic layer (Burano formation), forms the base of the Meso-Cenozoic sedimentary cover of most of the extruding wedges. The overall weakness of the Burano formation is related to the presence of evaporite (anydhrite) levels among dolostones [20] [76].

The proposed geodynamic interpretation [10] [12] also suggests that some mobility also characterizes the inner sector of the Apennines, even though such motion develops at lower rates and with a greater northward component with respect to the outer belt (Figure 8).

In summary, the proposed evolutionary reconstruction (Figure 7) suggests that at present the Adria-Ionian plate is a coherent block (with no significant breaks) moving almost in connection with Nubia. This view and the Nubia-Eurasia relative motion proposed by [4] can reconcile the geodetic velocity field in the southern Adria zone with the absence of a major Adria-Nubia decoupling zone.

\subsection{Present Kinematics and Tectonics of the Apennine Belt, Calabrian Arc and Sicily}

In the Apennine belt, the GPS kinematic pattern (Figure 2) points out a considerable variation of velocity from the outer to the inner sectors. This evidence is illustrated with a greater detail in Figure 9, where a tentative identification of roughly homogeneous kinematic domains is shown. The highest velocities ( $3-5 \mathrm{~mm} / \mathrm{y})$ and a prevailing NE ward orientation of vectors characterize the outermost belt, including the buried thrusts and folds under the Po Plain, while the lowest velocities $(<2 \mathrm{~mm} / \mathrm{y}$ ), with NW ward to Northward orientation, are observed in the innermost belt. These two sectors are separated by an axial zone, characterized by intermediate velocity values and orientations. In the Padanian zone lying north of the buried Apennine folds velocity values 


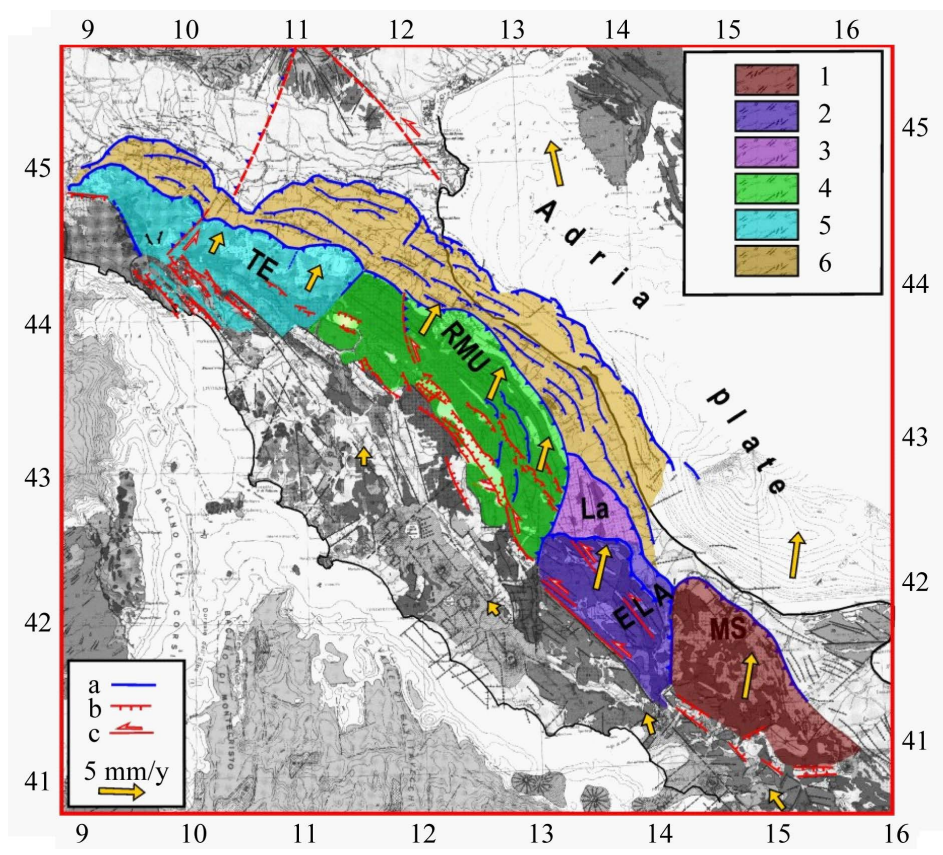

Figure 8. Orogenic wedges that constitute the outer mobile sector of the Apennine belt: 1) Molise-Sannio (MS); 2) Eastern Latium-Abruzzi (ELA); 3) Laga Units (La); 4) Romagna-Marche-Umbria (RMU); 5) TuscanyEmilia (TE); 6) Outermost buried folds. a, b, c) main compressional, extensional and transcurrent features. Yellow arrows indicate the presumed long term average kinematics of Adria, Apennine wedges and internal zones. Many details about the seismotectonic setting of the Apennine belt are provided by [10]-[12] [14] [49] [58] [59] [76].

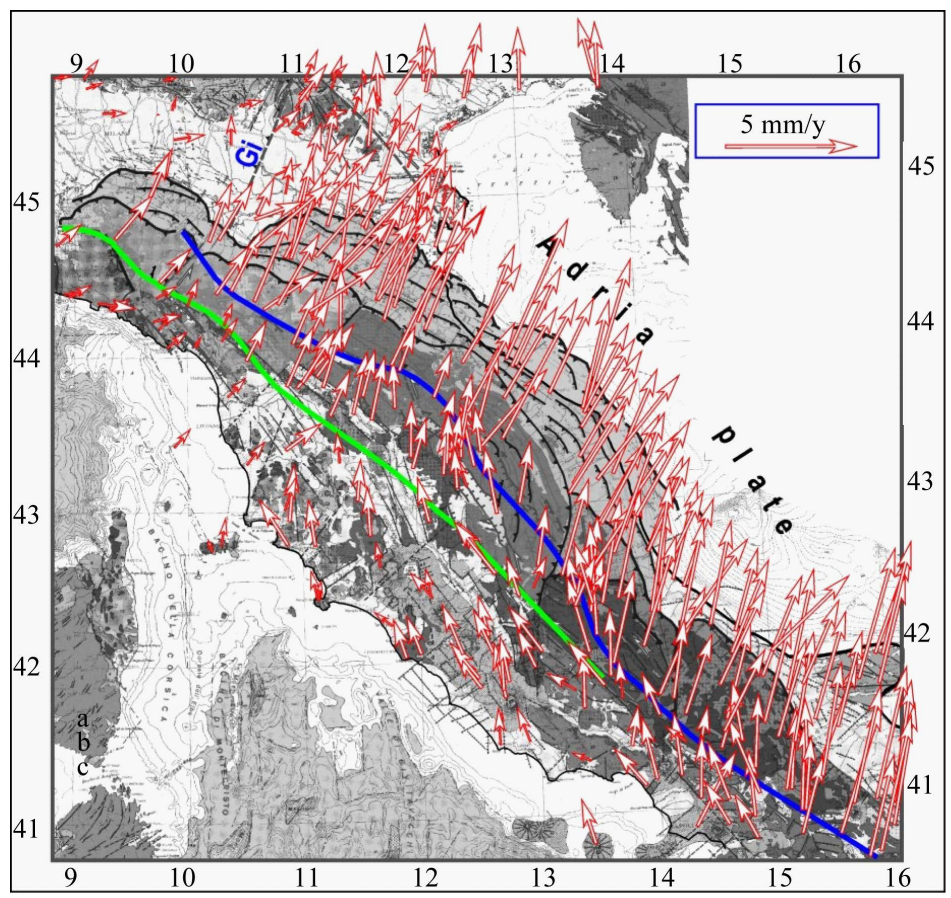

Figure 9. Tentative recognition of the roughly homogeneous kinematic domains in the Apennine belt. See text for comments. Gi = Giudicarie fault system. 
show a significant decrease. It can be noted that in the Padanian zone that lies west of the Giudicarie fault system the trends and rates of GPS vectors are significantly different from the ones in the surrounding zones. A discussion about the possible tectonic causes of this evidence is given by [21].

The GPS velocity field given in Figure 9 is compatible with the kinematic pattern of the Apennine belt deduced by the analysis of long-term evidence [8]-[14] [76] [77], with particular reference to the fact that the outer belt moves significantly faster and with a greater eastward component with respect to the inner belt (Figure 8).

The distribution of seismicity (Figure 10) in the Apennine belt shows an interesting correspondence between the alignments of major earthquakes and the transition zones from higher to lower geodetic velocities (Figure 9).

Other attempts at gaining insights into the present kinematics of the Apennine belt and surroundings by the analysis of geodetic data are reported in literature (see, e.g., the review given by [17]). Some of the considered velocity fields [78] [79] are similar to the one shown in Figure 2, but the proposed tectonic interpretations are drastically different from the one described above (Figure 7(d) and Figure 9), since they mostly invoke the gravitational sinking of the Adriatic subducted lithosphere beneath the Apennine belt as the main driving mechanism of the observed surface kinematics.

However, such view involves some major problems, as argued in the following. Above all, it must be considered that the development of the presumed slab roll-back and consequent trench retreat along the Apennine belt is described with considerable uncertainty in literature. In particular, most authors [80]-[82] suggest that the evidence of subducted lithosphere beneath the Apennine belt is lacking in large sectors of the trench zone. Thus, it is difficult to assume such a discontinuous process as the driving mechanism of the present velocity field in the Apennines, which is characterized by a fairly uniform distribution of rates and orientations all along the belt (Figure 2). Furthermore, the above interpretation can hardly explain why the inner Apennine belt has such a different kinematics with respect to the outer belt, as also noted by [17] Nocquet (2012). This last difficulty is also pointed out by the results of numerical modelling, which show that the NE-ward roll-back of the Adriatic plate is expected to induce a similar motion in the upper plate [83], that in this case corresponds to the inner (Tyrrhenian) side of the Apennines.

Other experiments [84] point out that slab roll-back, trench retreat and back arc extension are inhibited when the continental foreland of the subducted lithosphere enters the trench. Since such condition is present along most of the Apennine and Maghrebian trench zones, the plausibility of the slab pull mechanism in those sectors is debatable.

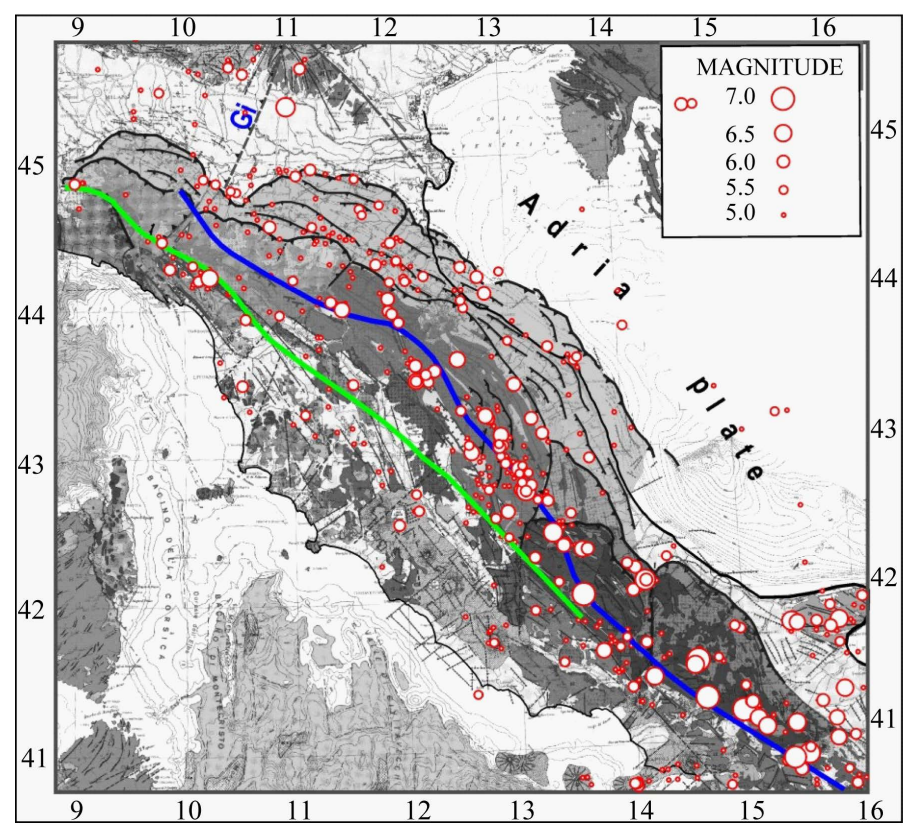

Figure 10. Distribution of major seismicity in the Apennine belt since 1000 A.D. [48]. The coloured lines are taken from Figure 9. 
Another major problem for the slab roll-back mechanism is explaining some major features of the GPS velocity field in the Calabrian Arc, i.e. the only belt sector where the presence of a well-developed slab is clearly documented by the distribution of deep seismicity [64]. In particular one should explain why in Calabria the GPS vectors are almost parallel to the main axis of the belt (Figure 2), and in Sicily the vectors are oriented towards the Tyrrhenian basin, i.e. about the opposite to what happens in the Apennines. In summary, it seems very difficult to understand why the invoked slab-pull mechanism would induce very different or even opposite effects on the kinematics of the various sectors of the retreating trench zone.

One could rather note that the geodetic velocity field, involving a roughly ENE motion of Calabria and a roughly northward motion of Sicily, is compatible with the present long-term kinematics provided for these two wedges by the proposed evolutionary reconstruction (Figure 7(d)). Considering the kinematic/tectonic pattern implied by such reconstruction, the present GPS velocity field in Calabria (Figure 2) could be taken as the result of two movements, one induced by the NNE ward motion of Nubia and the other given by a small SE ward motion (1 - 2 mmy) of the Calabrian wedge towards the Ionian domain.

This low value of the Ionian ward motion of Calabria and other evidence have led some authors [7] [42] [43] to suggest that the tectonic mechanism responsible for back arc activity in this sector of the trench is now almost inactive. However, this interpretation is not consistent with the fact that strong seismic activity has occurred in Calabria during the past centuries (1638, $\mathrm{M}=7.0$ and 6.9; $1783 \mathrm{M}=7.0,6.6$ and 7.0; $1905 \mathrm{M}=7.0 ; 1908 \mathrm{M}=$ 7.1, [48]), which indicates that southern Calabria is still undergoing strong deformation [67].

A discussion about this problem has been given by [49] [58] [63], who suggest that the recent/present tectonic setting in Calabria may have been influenced by a very rare major tectonic event that has considerably perturbed the strain and stress fields in the central Mediterranean region. It concerns the large westward displacement that the Anatolian-Aegean system underwent in response to the activation of the whole North Anatolian Fault System that was triggered by the very strong earthquake $(M=8)$ occurred in the easternmost sector of such system in 1939 [85]. In particular it is suggested that such large displacement of the Anatolian-Aegean-Balkan system may have caused a drastic increase of the E-W compressional stress in the northern Ionian and southern Adriatic zones, which might have consequently undergone crustal thickening and upward flexure. Such process may have significantly increased the resistance against the outward extrusion of the Calabrian wedge. This hypothesis could explain why after the post 1939 Anatolia's acceleration seismic activity in Calabria has undergone a considerable reduction [49] [58]. The last strong earthquake in that zone has occurred in $1947(\mathrm{M}=5.7)$. The length of the following seismic quiescence (68 years), concerning such seismicity level, is much longer than the average return period of major events (12 years) and of the longest inter-event time (41 years) in that zone [48].

The proposed geodynamic context [10]-[12] provides that the compressional regime induced by the convergence between Nubia (moving roughly NNE ward) and the Anatolian-Aegean system (moving westward) is accommodated by the simultaneous extrusion of the Calabrian wedge (towards the Ionian area) and of the Hyblean wedge (towards North/NNW). Thus, in the ongoing context, one could suppose that the present slowdown of Calabria's escape may emphasize the northward escape of the Hyblean wedge.

In the tectonic context proposed by [10] Mantovani et al. (2009) one could expect that at present the probability of strong earthquakes in Calabria is relatively low, whereas such probability may have increased in the decoupling zone between the above two wedges (in particular the Vulcano and Syracuse fault systems, Figure 7(c)) and in the northern front of the Hyblean wedge (northern Sicily and southernmost Tyrrhenian basin).

\section{Conclusions}

The present kinematic pattern of the Italian region, tentatively identified by GPS observations in hundreds of sites, provides significant insights into the geodynamic/tectonic setting in the central Mediterranean area. A significant number of data in the Apulian zone coherently indicate that the southern Adriatic domain moves roughly NE ward. This evidence creates a problem if the Nubia-Eurasia relative motion is taken from global kinematic models, since it implies a significant relative motion between Adria and Nubia, in contrast with the fact that no clear decoupling zone can be recognized between such plates. This major difficulty may be overcome if the alternative Nubia-Eurasia rotation pole proposed by [4] is taken into account. This solution may also account for some primary features of the Quaternary tectonic setting in the whole Mediterranean region.

To explain why the Nubia-Eurasia rotation pole provided by global kinematic models may be not reliable, [4] argue that the plate configuration adopted by such investigation is oversimplified, since it involves a two plates 
model (Nubia and Eurasia), notwithstanding that the distribution of seismic and tectonic features in the Mediterranean area suggests the presence of two microplates (Morocco and Iberia, Figure 1), not moving in close connection with the Nubia and Eurasia main plates.

It is worth noting that adopting the above four plate configuration the roughly NNE ward Nubia-Eurasia relative motion proposed by [4] can also account, within errors, for the North Atlantic kinematic constraints considered for the definition of the global kinematic models.

The GPS velocity field (Figure 2) clearly defines the kinematics of two Adriatic zones, one located in the southern part (Apulia) and the other located in the northernmost Adria domain (Venetian plain). If such kinematic constraints are interpreted as related to a rigid structure, the resulting Adria-Eurasia rotation pole is located in the Western Alps. Similar results have been obtained by the inversion of earthquake slip vectors in Periadriatic zones. This short-term solution would imply an independent motion between Nubia and Adria, whatever Nubia-Eurasia Euler pole is adopted, among the ones so far proposed. Since this result can hardly be reconciled with the lack of a decoupling zone between Nubia and Adria, we suppose that such evidence might result from a transient non-rigid behavior of the Adria plate. This hypothesis is supported by the fact that in the last tens of years (since 1930) most major Periadriatic earthquakes have occurred in the southern boundary zones (Northern Hellenides, Albanides, Southern Dinarides, Southern and Central Apennines). Such distribution of decoupling fault slips implies that at present the southern part of Adria can move in line with its long term behaviour, whereas the mobility of the northern Adria sector is still limited by the fact that in the last tens of years, the decoupling seismic zones in the Northern Dinarides, Eastern Southern Alps and Northern Apennines have not undergone significantactivations. This differential short-term behaviours would imply the development of a transient phase of internal deformation in the Adria plate. This effect, systematically developed during the analogous transient compressional phases occurred in the past evolution, could account for the presence in the central Adriatic area of the Mid Adriatic ridge, an uplifted structure explained as a consequence of longitudinal compression in the Adria domain.

The geodetic field in the Apennine belt, characterized by fairly different kinematic patterns in the inner and outer sectors of the belt, is compatible with the long term kinematic pattern deduced by the analysis of the Piocene-Quaternary deformation pattern in the central Mediterranean region [8] [10] [12] [14], whereas it can hardly be reconciled with the implications of the main alternative geodynamic mechanism often mentioned in literature, invoking the contribution of slab roll-back at the Adriatic-Apennine trench zone.

In the Calabrian Arc and Sicily the geodetic field is compatible with the hypothesis that, in response to the convergence of the confining plates (Nubia, Eurasia and the Anatolian-Aegean system), the Calabrian and Hyblean wedges are undergoing lateral escape, involving a roughly ENE ward motion for Calabria and a roughly Northward motion for the Hyblean block. At present, the second process is developing at higher rates with respect to the first one, due to the effects of the post 1939 large westward displacement of the Anatolian-Aegean system [49] [58].

\section{Acknowledgements}

We thank two anonymous reviewers for their constructive comments.

\section{References}

[1] DeMets, C., Gordon, R.G. and Argus, D.F. (2010) Geologically Current Plate Motions. Geophysical Journal International, 181, 1-80. http://dx.doi.org/10.1111/j.1365-246X.2009.04491.x

[2] Argus, D.F., Gordon, R.G., Heflin, M.B., Ma, C., Eanes, R.J., Willis, P., Peltier, W.R. and Owen, S.E. (2010) The Angular Velocities of the Plates and the Velocity of Earth's Centre from Space Geodesy. Geophysical Journal International, 180, 913-960. http://dx.doi.org/10.1111/j.1365-246X.2009.04463.x

[3] Altamimi, Z., Métivier, L. and Collilieux, X. (2012) ITRF2008 Plate Motion Model. Journal of Geophysical Research, 117, B07402. http://dx.doi.org/10.1029/2011JB008930

[4] Mantovani, E., Viti, M., Babbucci, D. and Albarello, D. (2007)Nubia-Eurasia Kinematics: an Alternative Interpretation from Mediterranean and North Atlantic Evidence. Annals of Geophysics, 50, 311-336.

[5] Malinverno, A. and Ryan, W.B.F. (1986) Extension in the Tyrrhenian Sea and Shortening in the Apennines as Result of Arc Migration Driven by Sinking of the Lithosphere. Tectonics, 5, 227-245.

http://dx.doi.org/10.1029/TC005i002p00227 
[6] Schellart, W.P. and Lister, G.S. (2004) Tectonic Models for the Formation of Arc-Shaped Convergent Zones and Backarc Basins. The Geological Society of America Special Paper, 383, 237-258.

http://dx.doi.org/10.1130/0-8137-2383-3(2004)383[237:tmftfo]2.0.co;2

[7] Faccenna, C., Funiciello, F., Civetta, L., D’Antonio, M., Moroni, M. and Piromallo, C. (2007) Slab Disruption, Mantle Circulation, and the Opening of the Tyrrhenian Basins. The Geological Society of America Special Paper, 418, 153169. http://dx.doi.org/10.1130/2007.2418(08)

[8] Mantovani, E., Babbucci, D., Viti, M., Albarello, D., Mugnaioli, E., Cenni, N. and Casula, G. (2006) Post-Late Miocene Kinematics of the Adria Microplate: Inferences from Geological, Geophysical and Geodetic data. In: Pinter, N., Grenerczy, G., Weber, J., Stein, S. and Medak, D., Eds., The Adria Microplate: GPS Geodesy, Tectonics and Hazard, Vol. 61, NATO Science Series IV-Earth and Environmental Sciences, Springer, 51-69. http://dx.doi.org/10.1007/1-4020-4235-3_04

[9] Mantovani, E., Viti, M., Babbucci, D. and Tamburelli, C. (2007) Major Evidence on the Driving Mechanism of the Tyrrhenian Apennines Trench-Arc Back Arc System from CROP Seismic Data. Bollettino Della Societa Geologica Italiana, 126, 459-471.

[10] Mantovani, E., Babbucci, D., Tamburelli, C. and Viti, M. (2009) A Review on the Driving Mechanism of the Tyrrhenian-Apennines system: Implications for the Present Seismotectonic Setting in the Central-Northern Apennines. Tectonophysics, 476, 22-40. http://dx.doi.org/10.1016/j.tecto.2008.10.032

[11] Mantovani, E., Viti, M., Babbucci, D., Tamburelli, C., Cenni, N., Baglione, M. and D’Intinosante, V. (2014) Generation of Back-Arc Basins as Side Effect of Shortening Processes: Examples from the Central Mediterranean. International Journal of Geosciences, 5, 1062-1079. http://dx.doi.org/10.4236/ijg.2014.510091

[12] Viti, M., Mantovani, E., Babbucci, D. and Tamburelli, C. (2006) Quaternary Geodynamics and Deformation Pattern in the Southern Apennines: Implications for Seismic Activity. Bollettino Della Societa Geologica Italiana, 125, 273-291.

[13] Viti, M., Mantovani, E., Babbucci, D. and Tamburelli, C. (2009) Generation of Trench-Arc-Back-Arc Systems in the Western Mediterranean Region Driven by Plate Convergence. Bollettino Della Societa Geologica Italiana, 128, 89106.

[14] Viti, M., Mantovani, E., Babbucci, D. and Tamburelli, C. (2011) Plate Kinematics and Geodynamics in the Central Mediterranean. Journal of Geodynamics, 51, 190-204. http://dx.doi.org/10.1016/j.jog.2010.02.006

[15] DeMets, C., Gordon, R.G., Argus, D.F. and Stein, S. (1990) Current Plate Motions. Geophysical Journal International, 101, 425-478. http://dx.doi.org/10.1111/j.1365-246X.1990.tb06579.x

[16] DeMets, C., Gordon, R.G., Argus, D.F. and Stein, S. (1994) Effect of Recent Revisions to the Geomagnetic Reversal Time Scale on Estimates of Current Plate Motions. Geophysical Research Letters, 21, 2191-2194. http://dx.doi.org/10.1029/94GL02118

[17] Nocquet, J.-M. (2012) Present-Day Kinematics of the Mediterranean: A Comprehensive Overview of GPS Results. Tectonophysics, 579, 220-242. http://dx.doi.org/10.1016/j.tecto.2012.03.037

[18] Herring, T.A., King, R.W. and McClusky, S.C. (2010) GAMIT Reference Manual, GPS Analysis at MIT, Release 10.4. Department of Earth, Atmospheric and Planetary Sciences, Massachusetts Institute of Technology, Cambridge, USA.

[19] Dong, D., Herring, T.A. and King, R.W. (1998) Estimating Regional Deformation from a Combination of Space and Terrestrial Geodetic Data. Journal of Geodesy, 72, 200-214. http://dx.doi.org/10.1007/s001900050161

[20] Cenni, N., Mantovani, E., Baldi, P. and Viti, M. (2012) Present Kinematics of Central and Northern Italy from Continuous GPS Measurements. Journal of Geodynamics, 58, 62-72. http://dx.doi.org/10.1016/j.jog.2012.02.004

[21] Cenni, N., Viti, M., Baldi, P., Mantovani, E., Bacchetti, M. and Vannucchi, A. (2013) Present Vertical Movements in Central and Northern Italy from GPS Data: Possible Role of Natural and Anthropogenic Causes. Journal of Geodynamics, 71, 74-85. http://dx.doi.org/10.1016/j.jog.2013.07.004

[22] Herring, T.A., King, R.W. and McClusky, S.C. (2010) Global Kalman Filter VLBI and GPS Analysis Program, GLOBK Reference Manual, Release 10.4. Department of Earth, Atmospheric and Planetary Sciences, Massachusetts Institute of Technology, Cambridge, USA.

[23] Blewitt, G. and Lavallée, D. (2002) Effect of Annual Signals on Geodetic Velocity. Journal of Geophysical Research, 107, 2145. http://dx.doi.org/10.1029/2001JB000570

[24] Bos, M.S., Fernandes, R.M.S., Williams, S.D.P. and Bastos, L. (2008) Fast Error Analysis of Continuous GPS Observations. Journal of Geodesy, 82, 157-166. http://dx.doi.org/10.1007/s00190-007-0165-x

[25] Bos, M.S., Bastos, L. and Fernandes, R.M.S. (2010) The Influence of Seasonal Signals on the Estimation of the Tectonic Motion in Short Continuous GPS Time-Series. Journal of Geodynamics, 49, 205-209. http://dx.doi.org/10.1016/j.jog.2009.10.005

[26] Hackl, M., Malservisi, R., Hugentobler, U. and Wonnacott, R. (2011) Estimation of Velocity Uncertainties from GPS 
Time Series: Examples from the Analysis of the South African TrigNet Network. Journal of Geophysical Research, 116, B11404. http://dx.doi.org/10.1029/2010jb008142

[27] Santamaría-Gómez, A., Bouin, M.N., Collilieux, X. and Wöppelmann, G. (2011) Correlated Errors in GPS Position Time Series: Implications for Velocity Estimates. Journal of Geophysical Research, 116, B01405. http://dx.doi.org/10.1029/2010jb007701

[28] Williams, S.D.P., Bock, Y., Fang, P., Jamason, P., Nikolaidis, R-M., Prawirodirdjo, L., Miller, M. and Johnson, J. (2004) Error Analysis of Continuous GPS Position Time Series. Journal of Geophysical Research, 109, B03412. http://dx.doi.org/10.1029/2003jb002741

[29] Williams, S.D.P. (2008) CATS: GPS Coordinate Time Series Analysis Software. GPS Solutions, 12, 147-153. http://dx.doi.org/10.1007/s10291-007-0086-4

[30] Bos, M.S., Fernandes, R.M.S., Williams, S.D.P. and Bastos, L. (2013) Fast Error Analysis of Continuous GNSS Observations with Missing Data. Journal of Geodesy, 87, 351-360. http://dx.doi.org/10.1007/s00190-012-0605-0

[31] Nicolai, C. and Gambini, R. (2007) Structural Architecture of the Adria Platform-and-Basin System. Bollettino Della Societa Geologica Italiana (Italian Journal of Geosciences), Special Issue 7, 21-37.

[32] Fantoni, R. and Franciosi, R. (2010) Tectono-sedimentary Setting of the Po Plain and Adriatic Foreland. Rendiconti Lincei - Scienze Fisiche e Naturali, 21, S197-S209. http://dx.doi.org/10.1007/s12210-010-0102-4

[33] Anderson, H. and Jackson, J. (1987) Active Tectonics of the Adriatic Region. Geophysical Journal International, 91, 937-983. http://dx.doi.org/10.1111/j.1365-246X.1987.tb01675.x

[34] Scisciani, V. and Calamita, F. (2009) Active Intraplate Deformation within Adria: Examples from the Adriatic Region. Tectonophysics, 476, 57-72. http://dx.doi.org/10.1016/j.tecto.2008.10.030

[35] Weber, J., Vrabec, M., Pavlovčič-Prešeren, P., Dixon, T., Jiang, Y. and Stopar, B. (2010) GPS-Derived Motion of the Adriatic Microplate from Istria Peninsula and Po Plain Sites, and Geodynamic Implications. Tectonophysics, 483, 214-222. http://dx.doi.org/10.1016/j.tecto.2009.09.001

[36] Westaway, R. (1990) Present-Day Kinematics of the Plate Boundary Zone between Africa and Europe, from the Azores to the Aegean. Earth and Planetary Science Letters, 96, 393-406. http://dx.doi.org/10.1016/0012-821X(90)90015-P

[37] Console, R., Di Giovambattista, R., Favali, P., Presgrave, B.W. and Smriglio, G. (1993) Seismicity of the Adriatic Microplate. Tectonophysics, 218, 343-354. http://dx.doi.org/10.1016/0040-1951(93)90323-C

[38] Favali, P., Funiciello, R., Mattietti, G., Mele, G. and Salvini, F. (1993) An Active Margin Across the Adriatic Sea (Central Mediterranean Sea). Tectonophysics, 219, 109-117. http://dx.doi.org/10.1016/0040-1951(93)90290-Z

[39] Meletti, C., Patacca, E. and Scandone, P. (2000) Construction of a Seismotectonic Model: The Case of Italy. Pure and Applied Geophysics, 157, 11-35. http://dx.doi.org/10.1007/PL00001089

[40] Oldow, J.S., Ferranti, L., Lewis, D.S., Campbell, J.K., D’Argenio, B., Catalano, R., Pappone, G., Carmignani, L., Conti, P. and Aiken, C.L.V. (2002) Active Fragmentation of Adria, the North African Promontory, Central Mediterranean Orogeny. The Geological Society of America, 9, 779-782.

[41] Battaglia, M., Murray, M.H., Serpelloni, E. and Burgmann, R. (2004) The Adriatic Region: An Independent Microplate within the Africa-Eurasia Collision Zone. Geophysical Research Letters, 31, L09605. http://dx.doi.org/10.1029/2004gl019723

[42] Goes, S., Giardini, D., Jenny, S., Hollenstein, C., Kahle, H.G. and Geiger, A. (2004) A Recent Tectonic Reorganization in the South-Central Mediterranean. Earth and Planetary Science Letters, 225, 335-345. http://dx.doi.org/10.1016/j.epsl.2004.07.038

[43] Serpelloni, E., Anzidei, M., Baldi, P., Casula, G. and Galvani, G. (2005) Crustal Velocity and Strain-Rate Fields in Italy and Surrounding Regions: New Results from the Analysis of Permanent and Non-Permanent GPS Networks. Geophysical Journal International, 161, 861-880. http://dx.doi.org/10.1111/j.1365-246X.2005.02618.X

[44] D’Agostino, N., Avallone, A., Cheloni, D., D’Anastasio, E., Mantenuto, S. and Selvaggi, G. (2008) Active Tectonics of the Adriatic Region from GPS and Earthquake Slip Vectors. Journal of Geophysical Research, 113, B12413. http://dx.doi.org/10.1029/2008jb005860

[45] Babbucci, D., Tamburelli, C., Viti, M., Mantovani, E., Albarello, D., D’Onza, F., Cenni, N. and Mugnaioli, E. (2004) Relative Motion of the Adriatic with Respect to the Confining Plates: Seismological and Geodetic Constraints. Geophysical Journal International, 159, 765-775. http://dx.doi.org/10.1111/j.1365-246X.2004.02403.x

[46] Argnani, A. (2006). Some Issues regarding the Central Mediterranean Neotectonics. Bollettino di Geofisica Teorica ed Applicata, 47, 13-37.

[47] Finetti, I.R. and Del Ben, A. (2005) Crustal Tectono-stratigraphic Setting of the Adriatic Sea from new CROP Seismic Data. In: Finetti, I.R., Ed., Deep Seismic Exploration of the Central Mediterranean and Italy, CROP PROJECT. El- 
sevier, Amsterdam, 519-548 (Chapter 23).

[48] Rovida, A., Camassi, R., Gasperini, P. and Stucchi, M., Eds. (2011) CPTI11, the 2011 Version of the Parametric Catalogue of Italian Earthquakes. Milano, Bologna. http://emidius.mi.ingv.it/CPTI

[49] Viti, M., Mantovani, E., Babbucci, D., Cenni, N. and Tamburelli, C. (2015) Where the Next Strong Earthquake in the Italian Peninsula? Insights by a Deterministic Approach. Bollettino di Geofisica Teorica ed Applicata, 56, 329-350.

[50] Alasset, P.J. and Meghraoui, M. (2005) Active Faulting in the Western Pyrenees (France): Paleoseismic Evidence for Late Holocene Ruptures. Tectonophysics, 409, 39-54. http://dx.doi.org/10.1016/j.tecto.2005.08.019

[51] Lacan, P. and Ortuno, M. (2012) Active Tectonics of Pyrenees: A Review. Journal of Iberian Geology, 38, 9-30.

[52] Villamor, P., Capote, R., Stirling, M.W., Tsige, M., Berryman, K.R., Martínez-Díaz, J.J. and Martín-González, F. (2012) Contribution of Active Faults in the Intraplate Area of Iberia to Seismic Hazard: The Alentejo-Plasencia Fault. Journal of Iberian Geology, 38, 85-111. http://dx.doi.org/10.5209/rev_jige.2012.v38.n1.39207

[53] Roest, W.R. and Srivastava, S.P. (1991) Kinematics of the Plate Boundaries between Eurasia, Iberia, and Africa in the North Atlantic from the Late Cretaceous to the Present. Geology, 19, 613-616. http://dx.doi.org/10.1130/0091-7613(1991)019<0613:KOTPBB>2.3.CO;2

[54] Anguita, F. and Hernan, F. (2000) The Canary Islands: AUnifying Model. Journal of Volcanology and Geothermal Research, 103, 1-26. http://dx.doi.org/10.1016/S0377-0273(00)00195-5

[55] Geyer, A. and Martí, J. (2010) The Distribution of Basaltic Volcanism on Tenerife, Canary Islands: Implications on the Origin and Dynamics of the Rift Systems. Tectonophysics, 483, 310-326. http://dx.doi.org/10.1016/j.tecto.2009.11.002

[56] Martì, J., Pinel, V., Lopez, C., Geyer, A., Abella, R., Tarraga, M., Blanco, M.J., Castro, A. and Rodriguez, C. (2013) Causes and Mechanisms of the 2011-2012 El Hierro (Canary Islands) Submarine Eruption. Journal of Geophysical Research: Solid Earth, 118, 823-839. http://dx.doi.org/10.1002/jgrb.50087

[57] Saria, E., Calais, E., Altamimi, Z., Willis, P. and Farah, H. (2013) A New Velocity Field for Africa from Combined GPS and DORIS Space Geodetic Solutions: Contribution to the Definition of the African Reference Frame (AFREF). Journal of Geophysical Research: Solid Earth, 118, 1677-1697. http://dx.doi.org/10.1002/jgrb.50137

[58] Mantovani, E., Viti, M., Babbucci, D., Tamburelli, C., Cenni, N., Baglione, M. and D’Intinosante, V. (2015) Recognition of PeriAdriatic Seismic Zones Most Prone to Next Major Earthquakes: Insights from a Deterministic Approach. In: D’Amico, S., Ed., Earthquakes and Their Impact on Society. Springer Natural Hazard Series, Springer, 43-80.

[59] Mantovani, E., Viti, M., Babbucci, D., Tamburelli, C., Cenni, N., Baglione, M. and D’Intinosante,V. (2015) Present Tectonic Setting and Spatio-Temporal Distribution of Seismicity in the Apennine Belt. International Journal of Geosciences, 6, 429-454. http://dx.doi.org/10.4236/ijg.2015.64034

[60] Viti, M., D’Onza, F., Mantovani, E., Albarello, D. and Cenni, N. (2003) Post-seismic Relaxation and Earthquake Triggering in the Southern Adriatic Region. Geophysical Journal International, 153, 645-657. http://dx.doi.org/10.1046/j.1365-246X.2003.01939.x

[61] Viti, M., Mantovani, E., Cenni, N. and Vannucchi, A. (2012) Post-Seismic Relaxation: An Example of Earthquake Triggering in the Apennine Belt (1915-1920). Journal of Geodynamics, 61, 57-67. http://dx.doi.org/10.1016/j.jog.2012.07.002

[62] Viti, M., Mantovani, E., Cenni, N. and Vannucchi, A. (2013) Interaction of Seismic Sources in the Apennine Belt. Physics and Chemistry of the Earth, 63, 25-35. http://dx.doi.org/10.1016/j.pce.2013.03.005

[63] Mantovani, E., Viti, M., Babbucci, D., Cenni, N., Tamburelli, C. and Vannucchi, A. (2012) Middle Term Prediction of Earthquakes in Italy: Some Remarks on Empirical and Deterministic Approaches. Bollettino di Geofisica Teorica ed Applicata, 53, 89-111.

[64] Finetti, I.R. (2005) The Calabrian Arc and Subducting Ionian Slab from New CROP Seismic Data. In: Finetti, I.R., Ed., Deep Seismic Exploration of the Central Mediterranean and Italy, CROP PROJECT. Elsevier, Amsterdam, 393-412 (Chapter 17).

[65] Del Ben, A., Barnaba, C. and Taboga, A. (2008) Strike-slip Systems as the Main Tectonic Features in the Plio-Quaternary Kinematics of the Calabrian Arc. Marine Geophysical Researches, 29, 1-12. http://dx.doi.org/10.1007/s11001-007-9041-6

[66] Westaway, R. (1993) Quaternary Uplift of Southern Italy. Journal of Geophysical Research, 98, 741-772. http://dx.doi.org/10.1029/93JB01566

[67] Zecchin, M., Praeg, D., Ceramicola, S. and Muto, F. (2015) Onshore to Offshore Correlation of Regional Unconformities in the Plio-Pleistocene Sedimentary Successions of the Calabrian Arc (Central Mediterranean). Earth-Science Reviews, 142, 60-78. http://dx.doi.org/10.1016/j.earscirev.2015.01.006

[68] Moretti, I. and Royden, L. (1988) Deflection, Gravity Anomalies and Tectonics of Doubly Subducted Continental Lithosphere: Adriatic and Ionian Seas. Tectonics, 7, 875-893. http://dx.doi.org/10.1029/TC007i004p00875 
[69] Argnani, A., Frugoni, F., Cosi, R., Ligi, M. and Favali, P. (2001) Tectonics and Seismicity of the Apulian Ridge South of Salento Peninsula (Southern Italy). Annals of Geophysics, 44, 527-540.

[70] Chilovi, C., De Feyter, J. and Pompucci, A. (2000) Wrench Zone Reactivation in the Adriatic Block: The Example of the Mattinata Fault System (SE Italy). Bollettino Della Societa Geologica Italiana, 119, 3-8.

[71] Di Bucci, D. and Mazzoli, S. (2003) The October-November 2002 Molise Seismic Sequence (Southern Italy): An Expression of Adria Intraplate Deformation. The Geological Society of London, 160, 503-506. http://dx.doi.org/10.1144/0016-764902-152

[72] Tondi, E., Piccardi, L., Cacon, S., Kontny, B. and Cello, G. (2005) Structural and Time Constraints for Dextral Shear Along the Seismogenic Mattinata Fault (Gargano, Southern Italy). Journal of Geodynamics, 40, 134-152. http://dx.doi.org/10.1016/j.jog.2005.07.003

[73] Ferranti, L., Burrato, P., Pepe, F., Santoro, E., Mazzella, M.E., Morelli, D., Passaro, S. and Vannucci, G. (2014) An Active Oblique Contractional Belt at the Transition Between the Southern Apennines and Calabrian Arc: The Amendolara Ridge, Ionian Sea, Italy. Tectonics, 33, 2169-2194. http://dx.doi.org/10.1002/2014TC003624

[74] Tansi, C, Iovine, G. and Folino Gallo, M. (2005) Tettonica Attiva e Recente, e Manifestazioni Gravitative Profonde, Lungo il Bordo Orientale del Graben del Fiume Crati (Calabria Settentrionale). Bollettino Della Societa Geologica Italiana, 124, 563-578.

[75] Mirabella, F., Barchi, M., Lupattelli, A., Stucchi, E. and Ciaccio, M.G. (2008) Insights on the Seismogenic Layer Thickness from the Upper Crust Structure of the Umbria-Marche Apennines (Central Italy). Tectonics, 27, TC1010. http://dx.doi.org/10.1029/2007TC002134

[76] Mantovani, E., Viti, M., Cenni, N., Babbucci, D., Tamburelli, C., Baglione, M. and D’Intinosante, V. (2015) Seismotectonics and Present Seismic Hazard in the Tuscany-Romagna-Marche-Umbria Apennines (Italy). Journal of Geodynamics, 89, 1-14. http://dx.doi.org/10.1016/j.jog.2015.05.001

[77] Viti, M., Mantovani, E., Babbucci, D., Tamburelli, C., Cenni, N., Baglione, M. and D’Intinosante, V. (2015) Belt-Parallel Shortening in the Northern Apennines and Seismotectonic Implications. International Journal of Geosciences, 6, 938-961. http://dx.doi.org/10.4236/ijg.2015.68075

[78] Bennett, R.A., Serpelloni, E., Hreinsdóttir, S., Brandon, M.T., Buble, G., Basic., T., Casale, G., Cavaliere, A., Anzidei, M., Marjonovic, M., Minelli, G., Molli, G. and Montanari, A. (2012) Syn-Convergent Extension Observed Using the RETREAT GPS Network, Northern Apennines, Italy. Journal of Geophysical Research, 117, B04408. http://dx.doi.org/10.1029/2011jb008744

[79] Devoti, R., Esposito, A., Pietrantonio, G., Pisani, A.R. and Riguzzi, F. (2011) Evidence of Large Scale Deformation Patterns from GPS data in the Italian Subduction Boundary. Earth and Planetary Science Letters, 311, 230-241. http://dx.doi.org/10.1016/j.epsl.2011.09.034

[80] Spakman, W. and Wortel, R. (2004) A Tomographic View on Western Mediterranean Geodynamics. In: Cavazza, W., Roure, F., Spakman, W., Stampfli, G.M. and Ziegler, P., Eds., The TRANSMED Atlas, The Mediterranean Region from Crust to Mantle, 31-52. http://dx.doi.org/10.1007/978-3-642-18919-7_2

[81] Lucente, F.P., Margheriti, L., Piromallo, C. and Barruol, G. (2006) Seismic Anisotropy Reveals the Long Route of the Slab Through the Western-Central Mediterranean Mantle. Earth and Planetary Science Letters, 41, 517-529. http://dx.doi.org/10.1016/j.epsl.2005.10.041

[82] Scafidi, D. and Solarino, S. (2012) Can Local Earthquake Tomography Settle the Matter About Subduction in the Northern and Central Apennines? Response from a New High Resolution P Velocity and Vp/Vs Ratio 3-D Model. Tectonophysics, 554-557, 63-73. http://dx.doi.org/10.1016/j.tecto.2012.06.007

[83] Schellart, W.P. and Moresi, L. (2013) A New Driving Mechanism for Backarc Extension and Backarc Shortening Through Slab Sinking Induced Toroidal And Poloidal Mantle Flow: Results from Dynamic Subduction Models with an Overriding Plate. Journal of Geophysical Research: Solid Earth, 118, 3221-3248. http://dx.doi.org/10.1002/jgrb.50173

[84] Magni, V., Van Hunen, J., Funiciello, F. and Faccenna, C. (2012) Numerical Models of Slab Migration in Continental Collision Zones. Solid Earth, 3, 293-306. http://dx.doi.org/10.5194/se-3-293-2012

[85] Barka, A.A. (1996) Slip Distribution along the North Anatolian Fault Associated with the Large Earthquakes of the Period 1939 to 1967. Bulletin of the Seismological Society of America, 86, 1238-1254. 
Appendix. Velocities of the GPS sites considered in this study in the ITRF2008 reference frame [3]. $\mathrm{N}=$ number of effective observation days. $\mathrm{T}=$ observation time interval. Lon, Lat and $\mathrm{H}=$ station coordinates (longitude ${ }^{\circ} \mathrm{E}$, latitude ${ }^{\circ} \mathrm{N}$ and height above the sea level). $\mathrm{V}_{\mathrm{N}}$ and $\sigma \mathrm{V}_{\mathrm{N}}, \mathrm{V}_{\mathrm{E}}$ and $\sigma \mathrm{V}_{\mathrm{E}}, \mathrm{V}_{\mathrm{H}}$ and $\sigma \mathrm{V}_{\mathrm{H}}=$ North, East and Vertical components of the site velocity and related uncertainties (in $\mathrm{mm} / \mathrm{yr}$ ). The methodology adopted for the analysis of geodetic measurements is described by [20]-[21].

\begin{tabular}{|c|c|c|c|c|c|c|c|c|c|c|c|}
\hline Code & $\mathbf{N}$ & $\mathrm{T}(\mathrm{yr})$ & Lon. & Lat. & $\mathbf{H}(\mathbf{m})$ & $\mathbf{V}_{\mathrm{N}}$ & $\sigma \mathrm{V}_{\mathrm{N}}$ & $\mathbf{V}_{\mathrm{E}}$ & $\sigma \mathbf{V}_{\mathrm{E}}$ & $\mathbf{V}_{\mathbf{H}}$ & $\sigma \mathbf{V}_{\mathbf{H}}$ \\
\hline ACCA & 2707 & 8.19 & 15.331 & 41.159 & 716.184 & 19.4 & 0.2 & 23.8 & 0.2 & 1.0 & 0.5 \\
\hline ACCE & 1870 & 5.69 & 6.988 & 44.476 & 1321.749 & 15.9 & 0.3 & 20.9 & 0.3 & 0.8 & 1.2 \\
\hline ACER & 2565 & 8.02 & 15.942 & 40.787 & 764.673 & 19.7 & 0.1 & 23.3 & 0.1 & 0.2 & 0.4 \\
\hline ACOM & 4074 & 12.03 & 13.515 & 46.548 & 1774.675 & 16.7 & 0.1 & 21.3 & 0.1 & 1.0 & 0.4 \\
\hline AFAL & 3818 & 12.07 & 12.175 & 46.527 & 2284.080 & 16.2 & 0.1 & 20.5 & 0.2 & 1.9 & 0.3 \\
\hline AGNE & 2143 & 7.24 & 7.140 & 45.468 & 2354.613 & 15.9 & 0.4 & 20.6 & 0.4 & 0.9 & 1.0 \\
\hline ALAT & 1911 & 6.32 & 13.384 & 41.673 & 286.625 & 17.6 & 0.5 & 21.6 & 0.2 & 0.4 & 0.8 \\
\hline ALBI & 1139 & 3.19 & 16.456 & 39.946 & 967.556 & 20.8 & 1.4 & 22.6 & 0.7 & 0.8 & 2.1 \\
\hline ALIF & 1948 & 6.26 & 14.335 & 41.327 & 167.661 & 17.3 & 0.4 & 22.3 & 0.4 & -1.9 & 1.3 \\
\hline ALIN & 1749 & 5.58 & 8.616 & 44.923 & 146.013 & 16.6 & 0.2 & 20.3 & 0.2 & -1.0 & 0.8 \\
\hline ALRA & 2279 & 8.44 & 14.034 & 41.734 & 969.786 & 19.4 & 0.5 & 23.6 & 0.6 & 1.1 & 1.3 \\
\hline ALSN & 1499 & 4.40 & 8.616 & 44.923 & 146.666 & 16.5 & 0.2 & 20.5 & 0.2 & -1.2 & 0.7 \\
\hline ALTA & 1285 & 4.13 & 16.559 & 40.823 & 537.773 & 19.9 & 0.2 & 23.9 & 0.2 & -0.4 & 0.7 \\
\hline AMAN & 933 & 3.08 & 16.077 & 39.120 & 58.864 & 19.2 & 0.5 & 23.4 & 0.5 & 1.2 & 1.6 \\
\hline AMPE & 2322 & 6.94 & 12.799 & 46.415 & 616.471 & 16.9 & 0.2 & 21.5 & 0.2 & 1.6 & 0.8 \\
\hline AMUR & 2988 & 8.93 & 16.604 & 40.907 & 549.439 & 19.8 & 0.1 & 23.6 & 0.1 & 0.1 & 0.2 \\
\hline ANCG & 4072 & 9.22 & 13.502 & 43.603 & 109.808 & 19.5 & 0.2 & 22.4 & 0.1 & 0.9 & 0.5 \\
\hline ANCN & 1412 & 3.96 & 13.532 & 43.607 & 213.879 & 20.5 & 0.4 & 23.1 & 0.3 & 0.2 & 0.6 \\
\hline ANGE & 1856 & 7.04 & 15.184 & 40.931 & 921.237 & 18.5 & 0.2 & 22.3 & 0.2 & 0.5 & 0.7 \\
\hline AO01 & 1855 & 6.51 & 7.321 & 45.737 & 659.784 & 15.9 & 0.3 & 20.3 & 0.2 & 1.7 & 0.8 \\
\hline AOST & 802 & 3.52 & 7.345 & 45.741 & 624.089 & 15.7 & 1.3 & 20.9 & 0.8 & 0.8 & 2.8 \\
\hline APRI & 2281 & 7.23 & 12.665 & 41.597 & 125.090 & 15.9 & 0.2 & 21.5 & 0.2 & 0.1 & 0.7 \\
\hline AQRA & 2587 & 9.07 & 13.374 & 42.366 & 747.263 & 17.2 & 0.2 & 21.0 & 0.3 & -1.1 & 0.8 \\
\hline AQSA & 715 & 2.90 & 16.084 & 39.721 & 881.751 & 18.5 & 0.8 & 23.0 & 0.9 & 1.1 & 2.5 \\
\hline AQUI & 4853 & 14.55 & 13.350 & 42.368 & 713.072 & 17.7 & 0.1 & 22.0 & 0.1 & -0.4 & 0.2 \\
\hline AQUM & 1370 & 4.02 & 13.467 & 42.328 & 640.549 & 17.3 & 0.4 & 21.9 & 0.4 & -2.8 & 1.0 \\
\hline ARBU & 1431 & 5.66 & 8.594 & 39.525 & 312.786 & 17.7 & 0.5 & 22.1 & 0.6 & -2.0 & 2.4 \\
\hline ARCA & 2213 & 7.05 & 16.226 & 39.367 & 279.696 & 19.0 & 0.2 & 24.0 & 0.2 & -0.5 & 0.7 \\
\hline ASCC & 1852 & 6.63 & 13.593 & 42.857 & 206.598 & 18.5 & 0.2 & 23.3 & 0.2 & 0.4 & 1.0 \\
\hline ASCG & 736 & 3.52 & 13.606 & 42.852 & 188.049 & 19.9 & 0.8 & 24.1 & 0.8 & -0.9 & 2.5 \\
\hline ASIA & 1992 & 6.90 & 11.525 & 45.866 & 1093.680 & 16.5 & 0.5 & 21.4 & 0.5 & -2.0 & 2.2 \\
\hline ASTI & 1529 & 5.29 & 8.203 & 44.906 & 207.045 & 16.6 & 0.4 & 19.9 & 0.5 & 0.1 & 1.5 \\
\hline ATBU & 1793 & 5.22 & 12.548 & 43.476 & 1046.290 & 18.8 & 0.2 & 22.0 & 0.3 & 0.6 & 0.7 \\
\hline
\end{tabular}




\section{Continued}

\begin{tabular}{|c|c|c|c|c|c|c|c|c|c|c|c|}
\hline ATFO & 1412 & 6.03 & 12.567 & 43.370 & 1020.427 & 18.4 & 0.3 & 23.7 & 0.4 & 2.0 & 0.9 \\
\hline ATLO & 1839 & 5.32 & 12.407 & 43.315 & 652.486 & 17.4 & 0.2 & 21.1 & 0.2 & 0.4 & 0.6 \\
\hline ATMI & 1091 & 3.48 & 12.267 & 43.334 & 573.059 & 16.5 & 0.7 & 22.4 & 0.7 & 3.3 & 1.9 \\
\hline ATTE & 1875 & 5.32 & 12.351 & 43.200 & 992.568 & 17.1 & 0.2 & 21.0 & 0.2 & -1.0 & 0.7 \\
\hline AVEL & 2057 & 6.54 & 14.783 & 40.912 & 420.250 & 17.8 & 0.2 & 21.8 & 0.3 & -0.1 & 1.0 \\
\hline AVZZ & 692 & 3.51 & 13.446 & 42.033 & 725.590 & 18.6 & 0.6 & 22.6 & 0.7 & -4.2 & 2.4 \\
\hline BAJA & 1862 & 5.57 & 7.719 & 43.904 & 921.789 & 17.1 & 0.2 & 21.6 & 0.2 & -2.3 & 0.7 \\
\hline BARC & 2345 & 6.94 & 12.564 & 46.193 & 528.451 & 17.3 & 0.4 & 20.5 & 0.4 & 1.6 & 1.6 \\
\hline BARS & 1400 & 4.80 & 13.582 & 42.337 & 1158.059 & 19.4 & 0.4 & 22.3 & 0.4 & -0.9 & 1.3 \\
\hline BART & 1042 & 3.11 & 15.018 & 41.414 & 689.698 & 18.9 & 0.5 & 23.3 & 0.5 & 0.7 & 1.7 \\
\hline BATE & 3866 & 12.06 & 12.185 & 43.709 & 757.243 & 17.3 & 0.1 & 21.7 & 0.1 & 1.0 & 0.3 \\
\hline BERT & 1329 & 5.64 & 12.134 & 44.148 & 343.660 & 19.5 & 0.2 & 22.6 & 0.2 & -1.3 & 0.7 \\
\hline BEVA & 2354 & 6.94 & 13.069 & 45.672 & 50.099 & 17.8 & 0.2 & 20.7 & 0.2 & -1.3 & 1.0 \\
\hline BEVE & 1876 & 5.62 & 9.769 & 44.194 & 144.713 & 16.4 & 0.2 & 20.9 & 0.2 & -0.5 & 0.7 \\
\hline BGDR & 851 & 2.98 & 11.895 & 43.889 & 740.822 & 17.9 & 0.7 & 21.5 & 0.7 & 3.3 & 2.2 \\
\hline BIEL & 3129 & 11.43 & 8.048 & 45.561 & 480.478 & 16.0 & 0.1 & 20.2 & 0.1 & 1.3 & 1.0 \\
\hline BL01 & 1647 & 7.28 & 12.203 & 46.137 & 453.718 & 17.3 & 0.2 & 20.7 & 0.2 & 1.5 & 0.7 \\
\hline BLGN & 2333 & 6.92 & 11.351 & 44.511 & 93.787 & 18.1 & 0.3 & 23.2 & 0.3 & -2.4 & 1.1 \\
\hline BLRA & 2357 & 8.53 & 13.560 & 41.810 & 419.397 & 17.2 & 0.5 & 20.3 & 0.8 & 1.2 & 1.6 \\
\hline ВОВB & 1971 & 7.40 & 9.383 & 44.771 & 370.529 & 17.5 & 0.3 & 21.6 & 0.2 & -1.4 & 0.8 \\
\hline BOLG & 3515 & 10.55 & 11.357 & 44.500 & 99.743 & 20.0 & 0.2 & 21.5 & 0.4 & -3.4 & 1.0 \\
\hline BOLO & 2409 & 7.49 & 11.329 & 44.488 & 140.131 & 17.8 & 0.4 & 22.9 & 0.2 & 0.7 & 0.8 \\
\hline BOLZ & 886 & 3.52 & 11.365 & 46.497 & 331.716 & 16.2 & 0.4 & 20.7 & 0.4 & 1.9 & 1.4 \\
\hline BORC & 2135 & 6.32 & 12.218 & 46.437 & 989.399 & 16.6 & 0.2 & 20.5 & 0.2 & 0.1 & 0.8 \\
\hline BORR & 2320 & 7.08 & 10.696 & 44.306 & 1023.384 & 17.1 & 0.2 & 22.6 & 0.2 & 0.5 & 0.5 \\
\hline BOSC & 1757 & 6.07 & 11.034 & 45.600 & 910.495 & 16.7 & 0.2 & 21.0 & 0.3 & 0.4 & 0.5 \\
\hline BOVA & 761 & 3.08 & 15.911 & 37.936 & 73.376 & 18.4 & 0.7 & 22.6 & 0.6 & -0.8 & 1.9 \\
\hline BRAS & 4952 & 14.55 & 11.113 & 44.122 & 901.198 & 17.1 & 0.1 & 21.4 & 0.1 & 1.1 & 0.2 \\
\hline BRBZ & 1453 & 4.55 & 11.941 & 46.797 & 903.768 & 16.3 & 0.2 & 20.6 & 0.2 & 1.0 & 0.8 \\
\hline BRIS & 1708 & 5.14 & 11.766 & 44.225 & 273.450 & 19.8 & 0.2 & 22.1 & 0.2 & -0.2 & 0.7 \\
\hline BRSE & 1314 & 4.02 & 12.084 & 46.100 & 381.380 & 17.6 & 0.5 & 19.3 & 0.4 & 1.7 & 1.0 \\
\hline BRU1 & 1233 & 3.64 & 9.725 & 44.236 & 172.146 & 16.0 & 0.4 & 21.4 & 0.3 & -0.3 & 1.0 \\
\hline BSSO & 3070 & 9.51 & 14.594 & 41.546 & 1004.668 & 18.9 & 0.2 & 22.9 & 0.2 & 0.6 & 0.8 \\
\hline BTAC & 2132 & 7.04 & 11.278 & 45.258 & 71.358 & 17.9 & 0.2 & 20.9 & 0.2 & -6.3 & 0.7 \\
\hline BUCU & 5166 & 14.54 & 26.126 & 44.464 & 143.208 & 12.5 & 0.1 & 22.9 & 0.1 & 2.3 & 0.2 \\
\hline BULG & 2671 & 8.59 & 15.378 & 40.078 & 899.314 & 18.1 & 0.1 & 22.4 & 0.1 & 0.3 & 0.3 \\
\hline
\end{tabular}




\section{Continued}

\begin{tabular}{|c|c|c|c|c|c|c|c|c|c|c|c|}
\hline BUSL & 1506 & 4.40 & 7.152 & 45.137 & 496.192 & 15.8 & 0.5 & 20.8 & 0.4 & -0.4 & 1.3 \\
\hline BUTE & 2649 & 7.55 & 19.057 & 47.481 & 180.789 & 14.5 & 0.2 & 22.2 & 0.2 & 0.2 & 0.6 \\
\hline BZRG & 4848 & 14.54 & 11.337 & 46.499 & 329.117 & 16.0 & 0.2 & 20.4 & 0.2 & 1.8 & 0.6 \\
\hline CA02 & 1697 & 6.49 & 9.000 & 39.011 & 69.053 & 16.6 & 0.3 & 21.6 & 0.3 & -0.3 & 0.8 \\
\hline CA04 & 1126 & 5.74 & 9.134 & 39.538 & 253.896 & 16.9 & 0.4 & 21.7 & 0.4 & 0.0 & 1.3 \\
\hline CA05 & 1339 & 4.39 & 9.118 & 39.238 & 94.708 & 16.6 & 0.2 & 21.8 & 0.2 & -0.1 & 0.7 \\
\hline CAFE & 3034 & 9.55 & 15.237 & 41.028 & 1066.318 & 18.9 & 0.1 & 22.1 & 0.1 & 1.2 & 0.3 \\
\hline CAFI & 2602 & 7.78 & 11.966 & 43.329 & 592.573 & 17.7 & 0.2 & 21.0 & 0.2 & 0.0 & 0.5 \\
\hline CAFV & 1114 & 3.36 & 11.939 & 45.670 & 98.418 & 17.5 & 0.4 & 21.5 & 0.4 & 0.2 & 1.0 \\
\hline CALA & 2536 & 7.55 & 11.164 & 43.868 & 117.980 & 17.7 & 0.2 & 22.1 & 0.2 & 1.4 & 0.8 \\
\hline CAMN & 1650 & 5.60 & 8.281 & 44.405 & 390.075 & 16.1 & 0.2 & 20.9 & 0.2 & -0.5 & 0.8 \\
\hline CAMU & 2215 & 6.95 & 11.978 & 43.259 & 313.253 & 17.5 & 0.2 & 21.5 & 0.4 & -0.3 & 0.7 \\
\hline CANL & 1526 & 4.40 & 8.293 & 44.722 & 205.512 & 16.0 & 0.2 & 21.0 & 0.2 & -0.6 & 0.7 \\
\hline CANV & 3366 & 11.16 & 12.435 & 46.008 & 965.915 & 17.5 & 0.4 & 20.0 & 0.3 & -0.1 & 0.5 \\
\hline CAOC & 1644 & 4.80 & 13.484 & 42.290 & 970.264 & 19.5 & 0.4 & 21.7 & 0.3 & -3.3 & 0.8 \\
\hline CAR1 & 1925 & 6.07 & 16.211 & 39.253 & 678.913 & 19.1 & 0.2 & 23.4 & 0.3 & 0.2 & 0.8 \\
\hline CARG & 3121 & 11.56 & 10.325 & 44.112 & 953.554 & 16.6 & 0.2 & 21.1 & 0.2 & 0.2 & 0.8 \\
\hline CARI & 1825 & 6.52 & 13.974 & 41.195 & 142.348 & 17.8 & 0.3 & 21.3 & 0.3 & -0.8 & 1.0 \\
\hline CARP & 2468 & 7.53 & 10.427 & 45.368 & 138.811 & 16.9 & 0.4 & 20.8 & 0.4 & 0.4 & 1.0 \\
\hline CARR & 846 & 3.52 & 10.081 & 44.069 & 116.677 & 16.1 & 0.8 & 20.5 & 0.8 & -1.3 & 1.9 \\
\hline CARZ & 2204 & 7.27 & 8.680 & 46.042 & 1165.291 & 16.4 & 0.2 & 20.4 & 0.2 & 1.1 & 0.7 \\
\hline CASG & 1731 & 6.04 & 14.941 & 40.269 & 90.414 & 17.7 & 0.3 & 21.6 & 0.3 & -0.9 & 0.8 \\
\hline CASP & 2702 & 8.10 & 10.865 & 42.791 & 374.042 & 17.4 & 0.2 & 19.8 & 0.2 & -1.5 & 0.4 \\
\hline CAST & 2682 & 8.33 & 10.405 & 44.432 & 755.744 & 18.0 & 0.2 & 21.7 & 0.2 & 0.7 & 0.5 \\
\hline CATU & 872 & 3.52 & 9.119 & 45.743 & 363.723 & 16.2 & 0.4 & 20.5 & 0.3 & 1.1 & 1.1 \\
\hline CDRA & 1750 & 8.62 & 13.720 & 42.368 & 1412.413 & 19.4 & 0.4 & 22.4 & 0.5 & -0.8 & 1.3 \\
\hline CDRU & 2864 & 8.88 & 15.305 & 40.490 & 1046.456 & 17.2 & 0.2 & 21.0 & 0.2 & 1.1 & 0.4 \\
\hline CECI & 1798 & 5.58 & 10.527 & 43.311 & 75.590 & 16.6 & 0.2 & 21.2 & 0.2 & 0.8 & 0.7 \\
\hline CELI & 938 & 3.75 & 16.509 & 39.403 & 1275.833 & 18.9 & 0.3 & 23.7 & 0.4 & 1.3 & 1.0 \\
\hline CERA & 3002 & 9.00 & 14.018 & 41.598 & 904.376 & 17.0 & 0.5 & 21.1 & 0.7 & 1.0 & 0.7 \\
\hline CERT & 3205 & 9.29 & 12.982 & 41.949 & 765.382 & 17.0 & 0.2 & 20.8 & 0.2 & 0.8 & 0.5 \\
\hline CESI & 2915 & 8.40 & 12.905 & 43.005 & 914.351 & 17.9 & 0.2 & 21.7 & 0.2 & 0.8 & 0.7 \\
\hline CGIA & 1488 & 4.55 & 12.266 & 45.207 & 57.543 & 16.8 & 0.2 & 20.8 & 0.3 & -5.9 & 0.7 \\
\hline CHAT & 868 & 3.52 & 7.624 & 45.753 & 645.789 & 15.0 & 0.7 & 19.9 & 0.5 & 2.0 & 1.4 \\
\hline CHIG & 791 & 3.52 & 11.281 & 45.543 & 228.102 & 15.8 & 0.5 & 21.3 & 0.4 & -1.0 & 1.3 \\
\hline CHIV & 1759 & 5.60 & 9.324 & 44.320 & 70.692 & 16.3 & 0.2 & 21.0 & 0.2 & -1.2 & 0.7 \\
\hline
\end{tabular}




\section{Continued}

\begin{tabular}{|c|c|c|c|c|c|c|c|c|c|c|c|}
\hline CIT1 & 1495 & 5.32 & 12.248 & 43.467 & 351.495 & 17.2 & 0.3 & 21.5 & 0.3 & 0.6 & 1.1 \\
\hline CITT & 1765 & 6.39 & 11.795 & 45.640 & 97.081 & 17.5 & 0.3 & 20.4 & 0.3 & -3.3 & 1.1 \\
\hline CIUF & 779 & 3.47 & 11.628 & 43.585 & 360.569 & 18.0 & 0.4 & 21.4 & 0.5 & -1.2 & 1.4 \\
\hline CODD & 1149 & 3.65 & 12.112 & 44.837 & 46.188 & 17.6 & 0.2 & 21.0 & 0.2 & -5.6 & 0.7 \\
\hline CODI & 2431 & 7.91 & 12.112 & 44.837 & 45.568 & 17.5 & 0.2 & 21.2 & 0.2 & -2.8 & 0.5 \\
\hline CODR & 2536 & 8.21 & 12.979 & 45.959 & 91.868 & 17.6 & 0.1 & 21.0 & 0.1 & 0.7 & 0.4 \\
\hline COLI & 2507 & 7.55 & 9.381 & 46.139 & 275.483 & 16.6 & 0.4 & 20.0 & 0.3 & 1.8 & 1.2 \\
\hline COLL & 2517 & 7.93 & 10.216 & 44.753 & 167.352 & 18.0 & 0.2 & 21.2 & 0.2 & 0.4 & 0.5 \\
\hline COLR & 1278 & 3.85 & 16.422 & 40.193 & 766.906 & 20.1 & 0.2 & 23.7 & 0.3 & 0.8 & 0.8 \\
\hline COMO & 4394 & 13.25 & 9.096 & 45.802 & 292.300 & 16.6 & 0.2 & 20.4 & 0.1 & 0.5 & 0.4 \\
\hline CONC & 887 & 3.52 & 11.009 & 44.922 & 64.470 & 18.5 & 0.6 & 21.4 & 0.5 & 0.1 & 2.1 \\
\hline CONI & 2120 & 6.22 & 13.393 & 42.412 & 1239.061 & 16.7 & 0.3 & 22.0 & 0.3 & -2.3 & 0.7 \\
\hline CONS & 2009 & 7.10 & 11.832 & 44.516 & 51.602 & 18.7 & 0.3 & 22.6 & 0.3 & -7.7 & 0.9 \\
\hline CORL & 2958 & 9.05 & 13.304 & 37.894 & 662.573 & 19.5 & 0.1 & 21.2 & 0.1 & 0.7 & 0.4 \\
\hline CRAC & 2828 & 9.55 & 16.435 & 40.381 & 360.734 & 19.6 & 0.1 & 23.5 & 0.1 & 1.4 & 0.3 \\
\hline CRMI & 2650 & 8.76 & 10.980 & 43.796 & 586.111 & 17.6 & 0.1 & 22.4 & 0.2 & -0.5 & 0.4 \\
\hline CRSN & 1542 & 4.40 & 8.106 & 45.192 & 211.678 & 16.4 & 0.2 & 20.1 & 0.2 & -0.2 & 0.7 \\
\hline CSSB & 2659 & 9.06 & 12.245 & 43.209 & 752.565 & 17.4 & 0.1 & 21.2 & 0.1 & 0.4 & 0.3 \\
\hline CTMG & 1311 & 6.74 & 11.384 & 44.573 & 72.224 & 20.0 & 0.4 & 24.8 & 0.5 & -3.5 & 1.6 \\
\hline CUCC & 2696 & 8.09 & 15.816 & 39.994 & 669.312 & 18.8 & 0.1 & 21.7 & 0.2 & 0.0 & 0.4 \\
\hline CUOR & 1510 & 4.40 & 7.648 & 45.388 & 483.105 & 16.0 & 0.2 & 20.3 & 0.2 & 0.7 & 0.8 \\
\hline DEMN & 1509 & 4.40 & 7.293 & 44.316 & 862.675 & 16.3 & 0.2 & 21.1 & 0.2 & -1.1 & 1.0 \\
\hline DEVE & 2072 & 7.29 & 8.261 & 46.314 & 1679.437 & 16.0 & 0.4 & 19.9 & 0.4 & 1.0 & 1.2 \\
\hline DOMS & 1507 & 4.40 & 8.286 & 46.119 & 365.635 & 15.6 & 0.2 & 19.8 & 0.3 & 0.9 & 1.1 \\
\hline EDEN & 1418 & 4.20 & 14.304 & 37.523 & 732.294 & 20.3 & 0.3 & 22.6 & 0.3 & 0.6 & 0.8 \\
\hline EIIV & 3074 & 9.54 & 15.082 & 37.514 & 88.870 & 18.0 & 0.2 & 22.9 & 0.2 & 1.6 & 0.7 \\
\hline ELBA & 4378 & 14.55 & 10.211 & 42.753 & 271.758 & 16.2 & 0.1 & 20.6 & 0.1 & -0.2 & 0.2 \\
\hline FAEZ & 2438 & 7.11 & 11.861 & 44.303 & 83.836 & 19.4 & 0.2 & 22.1 & 0.2 & -3.7 & 0.8 \\
\hline FASA & 2830 & 8.33 & 17.359 & 40.835 & 175.765 & 18.9 & 0.3 & 23.6 & 0.3 & -0.2 & 1.0 \\
\hline FDOS & 1201 & 4.75 & 11.724 & 46.304 & 1889.293 & 16.0 & 0.4 & 20.7 & 0.2 & 0.1 & 0.8 \\
\hline FERA & 2381 & 7.55 & 11.627 & 44.814 & 58.336 & 17.8 & 0.2 & 21.5 & 0.2 & 0.0 & 0.6 \\
\hline FERR & 2487 & 7.98 & 11.601 & 44.828 & 64.523 & 17.5 & 0.1 & 21.7 & 0.1 & 0.4 & 0.4 \\
\hline FIAN & 824 & 3.45 & 12.588 & 42.164 & 188.752 & 17.1 & 0.4 & 21.1 & 0.4 & -0.3 & 1.0 \\
\hline FIGL & 2467 & 7.55 & 11.474 & 43.619 & 188.037 & 18.0 & 0.2 & 21.4 & 0.2 & 0.9 & 0.6 \\
\hline FIOR & 829 & 3.52 & 11.585 & 42.834 & 753.139 & 17.3 & 0.5 & 21.3 & 0.6 & -0.9 & 1.5 \\
\hline FIRE & 2326 & 7.55 & 11.378 & 44.118 & 487.576 & 18.3 & 0.2 & 20.8 & 0.2 & 1.1 & 0.7 \\
\hline
\end{tabular}




\section{Continued}

\begin{tabular}{|c|c|c|c|c|c|c|c|c|c|c|c|}
\hline FISC & 1306 & 4.06 & 14.790 & 40.771 & 309.956 & 17.0 & 0.4 & 21.2 & 0.4 & -0.7 & 1.0 \\
\hline FOGG & 2749 & 8.09 & 15.532 & 41.452 & 148.366 & 18.8 & 0.3 & 23.1 & 0.3 & 0.3 & 1.0 \\
\hline FOL1 & 2245 & 7.55 & 12.699 & 42.955 & 296.337 & 18.1 & 0.2 & 20.8 & 0.2 & 0.4 & 0.8 \\
\hline FOND & 774 & 3.51 & 13.415 & 41.330 & 61.033 & 16.2 & 0.6 & 21.0 & 0.5 & 1.4 & 1.3 \\
\hline FORL & 1106 & 3.88 & 12.072 & 44.198 & 79.076 & 20.2 & 1.2 & 22.7 & 1.7 & -6.7 & 2.9 \\
\hline FOSS & 2323 & 7.55 & 12.807 & 43.689 & 176.511 & 18.9 & 0.2 & 23.2 & 0.2 & -0.2 & 0.6 \\
\hline FRES & 2696 & 8.84 & 14.669 & 41.974 & 404.688 & 18.7 & 0.1 & 23.3 & 0.1 & 0.1 & 0.4 \\
\hline FRMO & 1818 & 5.83 & 13.731 & 43.168 & 259.957 & 19.3 & 0.4 & 23.1 & 0.4 & 0.0 & 1.0 \\
\hline FRRA & 2651 & 9.05 & 14.292 & 42.418 & 92.550 & 18.6 & 0.2 & 22.9 & 0.2 & -0.2 & 0.7 \\
\hline FUSE & 2667 & 7.85 & 13.001 & 46.414 & 581.908 & 16.6 & 0.2 & 21.1 & 0.1 & 0.5 & 0.4 \\
\hline FVRA & 1857 & 5.77 & 13.669 & 37.318 & 392.526 & 18.6 & 0.2 & 21.0 & 0.2 & 0.9 & 0.8 \\
\hline GALF & 2659 & 8.63 & 14.567 & 37.711 & 731.387 & 19.2 & 0.2 & 20.7 & 0.2 & 1.3 & 0.4 \\
\hline GARI & 2048 & 6.00 & 12.249 & 44.677 & 47.750 & 17.8 & 0.4 & 21.6 & 0.4 & -2.7 & 1.3 \\
\hline GATE & 2045 & 6.05 & 14.910 & 41.513 & 470.811 & 19.1 & 0.2 & 23.1 & 0.2 & 0.2 & 0.7 \\
\hline GAVO & 1737 & 6.66 & 10.889 & 42.937 & 101.643 & 17.8 & 0.4 & 21.0 & 0.4 & 0.7 & 1.1 \\
\hline GAZZ & 2070 & 6.66 & 9.829 & 45.794 & 441.421 & 15.9 & 0.2 & 20.5 & 0.2 & 0.1 & 0.8 \\
\hline GBLM & 3151 & 10.45 & 14.026 & 37.990 & 1036.374 & 21.8 & 0.2 & 21.8 & 0.2 & 0.4 & 0.5 \\
\hline GENO & 4902 & 14.55 & 8.921 & 44.419 & 155.530 & 15.9 & 0.1 & 20.8 & 0.1 & -0.4 & 0.1 \\
\hline GENU & 1939 & 5.60 & 8.959 & 44.403 & 127.371 & 16.4 & 0.2 & 21.0 & 0.2 & -1.0 & 0.7 \\
\hline GEOT & 840 & 3.52 & 13.511 & 43.575 & 119.647 & 18.7 & 0.4 & 22.9 & 0.4 & 1.7 & 1.4 \\
\hline GINE & 816 & 3.52 & 13.376 & 43.121 & 385.195 & 19.4 & 0.4 & 24.0 & 0.5 & -1.3 & 1.3 \\
\hline GINO & 2512 & 7.47 & 16.758 & 40.578 & 319.137 & 18.9 & 0.4 & 24.1 & 0.4 & 3.0 & 1.3 \\
\hline GIOI & 2241 & 7.05 & 15.895 & 38.422 & 93.074 & 18.7 & 0.2 & 24.2 & 0.2 & 0.0 & 0.8 \\
\hline GIUR & 2578 & 7.47 & 18.430 & 40.124 & 121.857 & 18.6 & 0.3 & 23.8 & 0.3 & 0.4 & 1.0 \\
\hline GNAL & 1639 & 4.84 & 13.520 & 42.584 & 1048.599 & 17.9 & 0.4 & 23.1 & 0.4 & 0.9 & 0.8 \\
\hline GODE & 850 & 3.52 & 12.385 & 45.928 & 112.852 & 16.5 & 0.4 & 20.9 & 0.4 & -2.6 & 1.1 \\
\hline GORI & 2228 & 6.94 & 13.624 & 45.943 & 153.422 & 18.2 & 0.3 & 20.8 & 0.2 & -0.8 & 1.1 \\
\hline GOZZ & 1509 & 4.40 & 8.433 & 45.747 & 416.615 & 15.9 & 0.2 & 19.9 & 0.3 & 0.6 & 1.0 \\
\hline GRAM & 2124 & 7.04 & 13.871 & 42.976 & 64.432 & 17.9 & 0.2 & 23.3 & 0.2 & 0.0 & 0.7 \\
\hline GRO1 & 2197 & 6.73 & 15.101 & 41.067 & 404.419 & 18.3 & 0.2 & 22.3 & 0.2 & 0.9 & 0.5 \\
\hline GROA & 1674 & 6.64 & 11.109 & 42.782 & 68.056 & 17.4 & 0.5 & 20.5 & 0.5 & 1.1 & 1.6 \\
\hline GROG & 2668 & 8.99 & 9.892 & 43.426 & 241.061 & 16.5 & 0.1 & 21.1 & 0.1 & -0.5 & 0.3 \\
\hline GROT & 3445 & 10.15 & 15.060 & 41.073 & 499.875 & 18.2 & 0.1 & 22.5 & 0.1 & 1.1 & 0.4 \\
\hline GRZM & 2086 & 7.23 & 11.148 & 44.265 & 602.799 & 18.6 & 0.3 & 21.8 & 0.3 & 1.1 & 0.8 \\
\hline GUAR & 3106 & 9.13 & 13.312 & 41.794 & 718.772 & 16.1 & 0.2 & 20.5 & 0.2 & 0.8 & 0.4 \\
\hline GUAS & 2352 & 7.80 & 10.662 & 44.918 & 69.983 & 17.1 & 0.1 & 21.0 & 0.1 & -1.1 & 0.4 \\
\hline
\end{tabular}




\begin{tabular}{|c|c|c|c|c|c|c|c|c|c|c|c|}
\hline \multicolumn{12}{|c|}{ Continued } \\
\hline GUB2 & 2407 & 7.55 & 12.578 & 43.351 & 544.638 & 17.4 & 0.5 & 20.8 & 0.5 & 1.8 & 1.6 \\
\hline GUMA & 2291 & 7.27 & 13.335 & 43.063 & 651.612 & 18.8 & 0.2 & 23.6 & 0.2 & -0.1 & 0.8 \\
\hline HELM & 981 & 3.26 & 12.385 & 46.716 & 2451.269 & 15.9 & 0.4 & 20.4 & 0.4 & -0.9 & 1.3 \\
\hline HMDC & 2582 & 9.05 & 14.783 & 36.959 & 586.583 & 20.1 & 0.1 & 20.9 & 0.2 & -0.5 & 0.5 \\
\hline IENG & 3879 & 11.62 & 7.639 & 45.015 & 316.619 & 15.7 & 0.1 & 20.5 & 0.1 & 0.2 & 0.2 \\
\hline IGLE & 2364 & 7.05 & 8.533 & 39.311 & 283.047 & 17.2 & 0.2 & 22.1 & 0.2 & 1.5 & 0.8 \\
\hline IGMI & 2864 & 8.61 & 11.214 & 43.796 & 95.058 & 18.0 & 0.2 & 21.5 & 0.2 & 0.0 & 0.7 \\
\hline IMOL & 967 & 3.14 & 11.713 & 44.353 & 114.541 & 19.9 & 0.4 & 22.4 & 0.3 & -1.4 & 1.1 \\
\hline IMP3 & 1688 & 5.00 & 8.014 & 43.873 & 86.742 & 15.3 & 0.4 & 21.0 & 0.3 & 0.5 & 0.8 \\
\hline INGR & 4486 & 13.47 & 12.515 & 41.828 & 104.447 & 17.0 & 0.2 & 20.4 & 0.2 & 0.6 & 0.5 \\
\hline ISCH & 2594 & 7.98 & 15.897 & 41.904 & 373.486 & 18.9 & 0.3 & 23.6 & 0.3 & 1.1 & 1.0 \\
\hline ISER & 2048 & 6.99 & 14.236 & 41.600 & 550.741 & 18.3 & 0.5 & 22.7 & 0.5 & 0.7 & 1.6 \\
\hline ITIM & 2060 & 8.37 & 11.718 & 44.348 & 98.089 & 18.7 & 0.2 & 22.9 & 0.2 & -0.9 & 0.5 \\
\hline ITRA & 2030 & 10.51 & 14.002 & 42.659 & 105.440 & 18.9 & 0.3 & 23.0 & 0.3 & -1.0 & 1.2 \\
\hline ITRN & 2127 & 7.32 & 12.582 & 44.048 & 57.744 & 19.2 & 0.2 & 22.5 & 0.2 & -0.5 & 0.5 \\
\hline JOAN & 2754 & 8.06 & 13.416 & 46.184 & 1190.456 & 17.2 & 0.1 & 20.8 & 0.1 & 0.0 & 0.4 \\
\hline JOPP & 2928 & 8.87 & 15.886 & 38.607 & 553.819 & 18.6 & 0.1 & 23.7 & 0.1 & 0.4 & 0.4 \\
\hline KNJA & 638 & 3.18 & 22.255 & 43.567 & 291.064 & 12.1 & 0.8 & 24.0 & 0.7 & 2.0 & 2.4 \\
\hline LAGA & 2532 & 8.39 & 10.947 & 44.078 & 757.985 & 17.7 & 0.4 & 21.5 & 0.2 & -0.2 & 0.9 \\
\hline LAME & 837 & 3.08 & 16.235 & 38.878 & 54.485 & 19.0 & 0.6 & 23.5 & 0.5 & 1.6 & 1.8 \\
\hline LANU & 2198 & 7.29 & 9.548 & 39.883 & 510.315 & 15.7 & 0.2 & 21.5 & 0.3 & -0.1 & 0.8 \\
\hline LARI & 1985 & 7.53 & 14.922 & 41.810 & 434.758 & 19.0 & 0.2 & 23.5 & 0.3 & 0.5 & 0.8 \\
\hline LASP & 3054 & 9.07 & 9.840 & 44.073 & 87.143 & 16.4 & 0.1 & 21.1 & 0.1 & -0.4 & 0.3 \\
\hline LAT1 & 2538 & 7.54 & 12.901 & 41.471 & 97.943 & 16.9 & 0.2 & 21.2 & 0.2 & 5.3 & 1.7 \\
\hline LDNS & 864 & 3.04 & 10.827 & 45.167 & 81.086 & 16.5 & 0.7 & 21.4 & 0.8 & 0.2 & 2.2 \\
\hline LEGN & 1962 & 6.47 & 11.269 & 45.184 & 71.268 & 17.1 & 0.4 & 21.4 & 0.4 & 1.3 & 1.1 \\
\hline LERO & 1909 & 5.72 & 11.957 & 45.346 & 67.548 & 16.9 & 0.5 & 21.4 & 0.4 & -1.5 & 1.5 \\
\hline LINZ & 2605 & 7.55 & 14.283 & 48.310 & 335.084 & 15.5 & 0.2 & 20.6 & 0.2 & 1.2 & 0.8 \\
\hline LMPR & 868 & 3.46 & 10.891 & 43.811 & 112.430 & 18.0 & 0.4 & 21.7 & 0.5 & -0.3 & 1.4 \\
\hline LNSS & 3087 & 9.14 & 13.040 & 42.603 & 1150.857 & 17.8 & 0.2 & 21.7 & 0.2 & -0.1 & 0.6 \\
\hline LOAN & 1899 & 5.60 & 8.250 & 44.119 & 70.767 & 15.9 & 0.2 & 20.9 & 0.2 & -0.4 & 0.8 \\
\hline LOCR & 732 & 2.84 & 16.240 & 38.236 & 74.932 & 18.9 & 0.8 & 23.7 & 0.8 & -0.2 & 2.2 \\
\hline LPEL & 2105 & 7.26 & 14.183 & 42.047 & 816.469 & 19.2 & 0.4 & 24.7 & 0.7 & -1.2 & 1.6 \\
\hline LUCE & 1330 & 4.13 & 15.335 & 41.514 & 278.357 & 19.3 & 0.2 & 23.3 & 0.3 & -0.1 & 0.8 \\
\hline MOSE & 3610 & 10.76 & 12.493 & 41.893 & 120.573 & 16.9 & 0.2 & 20.3 & 0.2 & -0.9 & 0.7 \\
\hline MABZ & 1473 & 4.55 & 10.551 & 46.686 & 1092.071 & 16.0 & 0.3 & 21.0 & 0.3 & 2.3 & 0.8 \\
\hline
\end{tabular}




\section{Continued}

\begin{tabular}{|c|c|c|c|c|c|c|c|c|c|c|c|}
\hline MACE & 2345 & 7.55 & 13.451 & 43.294 & 307.111 & 19.3 & 0.2 & 23.8 & 0.2 & -0.5 & 0.6 \\
\hline MACO & 2064 & 7.55 & 8.770 & 40.269 & 637.708 & 17.7 & 0.2 & 21.6 & 0.2 & 1.8 & 0.8 \\
\hline MADA & 1749 & 5.11 & 10.366 & 43.748 & 56.867 & 16.4 & 0.2 & 21.2 & 0.2 & -0.1 & 0.8 \\
\hline MAGL & 745 & 3.52 & 13.588 & 43.138 & 310.111 & 19.2 & 0.4 & 24.5 & 0.5 & -0.9 & 1.5 \\
\hline MANO & 1024 & 3.10 & 14.059 & 42.273 & 192.080 & 19.4 & 0.5 & 22.1 & 0.5 & -2.5 & 2.2 \\
\hline MAON & 2870 & 9.22 & 11.131 & 42.428 & 228.386 & 16.1 & 0.1 & 21.0 & 0.1 & 0.0 & 0.4 \\
\hline MARG & 1131 & 3.40 & 9.767 & 45.571 & 207.066 & 16.2 & 0.4 & 20.0 & 0.4 & 1.6 & 1.4 \\
\hline MARI & 839 & 3.52 & 11.868 & 42.036 & 80.008 & 17.1 & 0.4 & 20.8 & 0.4 & -0.5 & 1.0 \\
\hline MARO & 805 & 3.52 & 11.669 & 45.748 & 158.145 & 16.1 & 0.4 & 20.4 & 0.4 & -0.1 & 1.0 \\
\hline MARS & 4317 & 14.55 & 5.354 & 43.279 & 61.813 & 16.1 & 0.2 & 19.9 & 0.2 & -0.4 & 0.6 \\
\hline MAT1 & 4913 & 14.20 & 16.705 & 40.649 & 534.520 & 18.7 & 0.2 & 23.4 & 0.1 & 0.5 & 0.4 \\
\hline MATE & 5119 & 14.55 & 16.705 & 40.649 & 535.647 & 19.4 & 0.1 & 23.3 & 0.1 & 0.7 & 0.2 \\
\hline MATG & 1053 & 3.46 & 16.705 & 40.649 & 535.597 & 20.2 & 0.4 & 23.3 & 0.3 & -0.1 & 0.9 \\
\hline MCEL & 2714 & 8.59 & 15.802 & 40.326 & 1058.870 & 19.9 & 0.1 & 23.2 & 0.1 & 0.1 & 0.4 \\
\hline MCIN & 1703 & 5.24 & 11.489 & 43.058 & 612.898 & 17.2 & 0.3 & 21.1 & 0.3 & 0.0 & 1.3 \\
\hline MCRV & 2937 & 9.99 & 15.168 & 40.783 & 1175.170 & 18.2 & 0.2 & 23.0 & 0.2 & 1.5 & 0.4 \\
\hline MDEA & 3710 & 12.48 & 13.436 & 45.925 & 165.698 & 18.2 & 0.1 & 20.8 & 0.1 & -0.5 & 0.4 \\
\hline MEDI & 4882 & 14.55 & 11.647 & 44.520 & 50.035 & 17.7 & 0.2 & 22.4 & 0.4 & -1.3 & 0.5 \\
\hline MELA & 2563 & 7.52 & 15.127 & 41.706 & 162.948 & 19.7 & 0.2 & 23.1 & 0.2 & -0.4 & 0.5 \\
\hline MFUS & 1009 & 3.67 & 14.834 & 41.058 & 615.298 & 18.2 & 0.3 & 21.1 & 0.3 & -1.2 & 0.9 \\
\hline MGAB & 2387 & 7.29 & 12.111 & 42.913 & 532.573 & 17.3 & 0.2 & 20.7 & 0.2 & 0.7 & 0.5 \\
\hline MLAG & 858 & 2.91 & 12.779 & 43.431 & 866.568 & 20.6 & 0.6 & 24.1 & 0.9 & 2.1 & 2.0 \\
\hline MLFT & 1391 & 4.47 & 16.604 & 41.196 & 85.649 & 19.3 & 0.2 & 23.1 & 0.2 & 0.0 & 0.8 \\
\hline MMNO & 1332 & 3.83 & 15.972 & 39.870 & 1013.482 & 17.9 & 0.6 & 20.1 & 0.7 & 2.5 & 1.5 \\
\hline MNIA & 1005 & 2.90 & 16.687 & 40.365 & 158.271 & 19.4 & 0.5 & 23.1 & 0.4 & 0.0 & 1.7 \\
\hline MO01 & 2553 & 9.21 & 10.900 & 44.641 & 94.916 & 18.6 & 0.1 & 22.2 & 0.1 & -4.4 & 0.6 \\
\hline MO02 & 3041 & 12.30 & 10.835 & 44.340 & 740.075 & 18.4 & 0.1 & 22.2 & 0.1 & 1.0 & 0.4 \\
\hline MO03 & 2028 & 9.22 & 10.625 & 44.360 & 837.512 & 19.1 & 0.1 & 22.0 & 0.1 & 0.3 & 0.5 \\
\hline MO05 & 2213 & 9.01 & 11.286 & 44.838 & 64.183 & 18.1 & 0.4 & 21.3 & 0.2 & 1.2 & 0.7 \\
\hline MOCA & 755 & 3.36 & 11.143 & 46.098 & 1147.213 & 16.8 & 0.5 & 22.0 & 0.5 & 0.9 & 1.9 \\
\hline MOCO & 2869 & 8.75 & 15.159 & 41.371 & 1072.633 & 19.4 & 0.2 & 22.9 & 0.2 & 0.0 & 0.4 \\
\hline MODE & 3001 & 8.62 & 10.949 & 44.629 & 92.171 & 19.6 & 0.1 & 21.4 & 0.1 & -3.8 & 0.4 \\
\hline MODR & 2615 & 8.93 & 13.881 & 41.146 & 375.608 & 16.9 & 0.1 & 20.6 & 0.1 & 0.3 & 0.4 \\
\hline MOGG & 2377 & 6.94 & 13.198 & 46.407 & 377.975 & 17.0 & 0.2 & 20.9 & 0.2 & 1.4 & 0.8 \\
\hline MONC & 2866 & 9.24 & 7.927 & 45.074 & 464.456 & 15.9 & 0.1 & 20.8 & 0.1 & -0.5 & 0.6 \\
\hline MONF & 865 & 3.52 & 8.453 & 45.134 & 177.743 & 16.6 & 0.5 & 20.8 & 0.4 & -1.5 & 1.3 \\
\hline
\end{tabular}




\begin{tabular}{|c|c|c|c|c|c|c|c|c|c|c|c|}
\hline \multicolumn{12}{|c|}{ Continued } \\
\hline MONT & 866 & 3.52 & 7.709 & 45.387 & 413.503 & 15.9 & 0.4 & 19.7 & 0.5 & 1.0 & 1.1 \\
\hline MONV & 1521 & 4.40 & 7.829 & 44.390 & 637.697 & 15.8 & 0.3 & 21.0 & 0.2 & -0.7 & 0.8 \\
\hline MONZ & 1663 & 4.80 & 9.272 & 45.577 & 227.205 & 15.9 & 0.2 & 20.8 & 0.2 & -0.2 & 0.8 \\
\hline MOPI & 2434 & 7.53 & 17.274 & 48.373 & 578.978 & 15.0 & 0.3 & 21.3 & 0.3 & 0.0 & 1.3 \\
\hline MOPS & 2885 & 8.29 & 10.949 & 44.629 & 92.203 & 19.0 & 0.1 & 21.8 & 0.1 & -2.7 & 0.5 \\
\hline MORB & 2517 & 7.55 & 9.567 & 46.134 & 325.059 & 16.0 & 0.3 & 20.4 & 0.2 & 2.0 & 0.9 \\
\hline MORO & 2120 & 7.10 & 12.619 & 42.053 & 201.594 & 17.2 & 0.2 & 20.6 & 0.3 & 0.3 & 0.7 \\
\hline MOST & 861 & 2.87 & 16.574 & 38.439 & 60.310 & 19.2 & 0.6 & 24.6 & 0.6 & 1.2 & 1.8 \\
\hline MOZ2 & 3245 & 9.22 & 10.544 & 43.979 & 156.754 & 17.3 & 0.2 & 21.4 & 0.2 & -0.6 & 1.1 \\
\hline MPRA & 4203 & 12.53 & 12.988 & 46.241 & 808.564 & 16.5 & 0.2 & 20.6 & 0.1 & -0.1 & 0.3 \\
\hline MRGE & 2675 & 8.86 & 7.061 & 45.770 & 1722.774 & 15.4 & 0.2 & 19.7 & 0.2 & 0.2 & 0.7 \\
\hline MRLC & 3238 & 9.65 & 15.489 & 40.756 & 631.484 & 19.9 & 0.2 & 23.9 & 0.1 & 1.2 & 0.4 \\
\hline MRRA & 2621 & 8.67 & 13.916 & 42.885 & 61.886 & 18.9 & 0.2 & 23.6 & 0.2 & -1.0 & 0.7 \\
\hline MRVN & 2732 & 9.17 & 16.196 & 41.061 & 593.655 & 19.7 & 0.1 & 23.3 & 0.1 & 0.7 & 0.3 \\
\hline MSAG & 2879 & 9.15 & 15.910 & 41.712 & 881.257 & 19.1 & 0.1 & 23.3 & 0.1 & 0.1 & 0.3 \\
\hline MSEL & 3603 & 10.86 & 11.647 & 44.520 & 49.272 & 18.4 & 0.1 & 22.0 & 0.1 & -1.5 & 0.3 \\
\hline MSRU & 2620 & 8.48 & 15.508 & 38.264 & 396.749 & 20.1 & 0.1 & 23.3 & 0.1 & -1.3 & 0.4 \\
\hline MT01 & 2106 & 6.33 & 12.201 & 45.749 & 98.576 & 17.7 & 0.2 & 20.6 & 0.2 & 0.7 & 0.7 \\
\hline MTRA & 2100 & 9.07 & 13.240 & 42.528 & 995.834 & 19.0 & 0.6 & 22.3 & 0.5 & 0.5 & 1.7 \\
\hline MTSN & 2448 & 8.59 & 15.751 & 40.266 & 1132.323 & 19.2 & 0.1 & 23.2 & 0.1 & 1.1 & 0.4 \\
\hline MTTG & 2558 & 9.52 & 15.700 & 38.003 & 544.100 & 18.1 & 0.2 & 23.9 & 0.1 & 0.7 & 0.4 \\
\hline MTTO & 2756 & 10.01 & 12.993 & 42.456 & 1738.067 & 16.7 & 0.2 & 21.8 & 0.3 & 0.3 & 0.7 \\
\hline MUR1 & 948 & 2.91 & 12.525 & 43.263 & 883.051 & 18.0 & 0.8 & 21.8 & 0.9 & 1.8 & 2.1 \\
\hline MURA & 1259 & 4.03 & 9.566 & 39.424 & 67.838 & 16.3 & 0.4 & 22.5 & 0.4 & 3.1 & 1.3 \\
\hline MVAL & 3109 & 9.06 & 12.407 & 43.382 & 638.322 & 17.6 & 0.1 & 21.5 & 0.1 & 0.9 & 0.3 \\
\hline NAPO & 1972 & 6.54 & 14.276 & 40.870 & 127.707 & 18.1 & 0.2 & 23.5 & 0.2 & 0.0 & 0.8 \\
\hline NERO & 851 & 3.52 & 8.455 & 45.712 & 380.995 & 15.7 & 0.4 & 20.6 & 0.5 & 0.3 & 1.1 \\
\hline NETT & 752 & 3.48 & 12.648 & 41.461 & 100.197 & 16.9 & 0.3 & 21.4 & 0.4 & -1.1 & 0.9 \\
\hline NICO & 1688 & 5.55 & 14.327 & 41.047 & 100.766 & 17.7 & 0.2 & 22.0 & 0.3 & -0.3 & 0.8 \\
\hline NOCI & 3034 & 9.98 & 17.064 & 40.789 & 437.667 & 19.3 & 0.1 & 24.3 & 0.1 & 1.4 & 0.3 \\
\hline NOT1 & 4928 & 14.55 & 14.990 & 36.876 & 126.342 & 19.9 & 0.1 & 21.4 & 0.1 & -0.4 & 0.1 \\
\hline NOVE & 2004 & 6.15 & 12.588 & 45.668 & 47.962 & 17.9 & 0.4 & 21.1 & 0.4 & -2.4 & 1.1 \\
\hline NOVR & 1537 & 4.40 & 8.614 & 45.447 & 218.628 & 16.7 & 0.2 & 20.8 & 0.2 & 0.2 & 0.7 \\
\hline NPAZ & 859 & 3.86 & 20.519 & 43.140 & 549.504 & 14.1 & 0.2 & 23.6 & 0.2 & 0.8 & 0.8 \\
\hline NU01 & 1470 & 7.14 & 9.313 & 40.315 & 586.715 & 16.9 & 0.4 & 21.6 & 0.4 & 0.4 & 1.3 \\
\hline OATO & 2276 & 7.24 & 7.765 & 45.042 & 658.824 & 15.5 & 0.2 & 20.6 & 0.2 & 0.6 & 0.5 \\
\hline
\end{tabular}




\section{Continued}

\begin{tabular}{|c|c|c|c|c|c|c|c|c|c|c|c|}
\hline OCRA & 2270 & 8.57 & 13.039 & 42.050 & 878.220 & 17.2 & 0.3 & 20.3 & 0.4 & 1.0 & 0.9 \\
\hline ODEZ & 1505 & 4.38 & 12.489 & 45.788 & 70.431 & 17.7 & 0.2 & 21.1 & 0.2 & -1.2 & 0.7 \\
\hline OLGI & 2379 & 7.30 & 12.355 & 42.055 & 207.877 & 17.5 & 0.2 & 20.6 & 0.3 & 0.0 & 0.7 \\
\hline OMBR & 3396 & 12.06 & 11.560 & 43.733 & 1093.388 & 17.4 & 0.1 & 21.3 & 0.1 & 0.2 & 0.2 \\
\hline ORID & 4762 & 14.55 & 20.794 & 41.127 & 773.006 & 11.6 & 0.1 & 24.0 & 0.1 & 0.3 & 0.4 \\
\hline ORZI & 704 & 3.52 & 9.921 & 45.409 & 132.538 & 16.0 & 0.4 & 21.2 & 0.4 & -0.9 & 1.3 \\
\hline OSIM & 839 & 3.48 & 13.482 & 43.481 & 195.886 & 18.8 & 0.4 & 23.5 & 0.4 & 0.8 & 1.4 \\
\hline OTRA & 1414 & 6.58 & 13.646 & 41.955 & 729.191 & 18.6 & 0.7 & 22.3 & 0.5 & -1.6 & 1.6 \\
\hline OVRA & 2635 & 8.67 & 13.515 & 42.138 & 1432.100 & 19.6 & 0.5 & 21.4 & 0.5 & -0.3 & 1.3 \\
\hline PACA & 3511 & 12.21 & 14.556 & 40.871 & 128.104 & 17.0 & 0.1 & 21.0 & 0.1 & -1.1 & 0.2 \\
\hline PADO & 4395 & 13.64 & 11.896 & 45.411 & 64.712 & 16.7 & 0.1 & 20.8 & 0.1 & -1.2 & 0.3 \\
\hline PAGA & 717 & 3.52 & 13.466 & 42.362 & 716.999 & 16.6 & 0.5 & 22.1 & 0.5 & -4.0 & 1.5 \\
\hline PAGL & 1779 & 5.27 & 14.498 & 42.164 & 287.607 & 19.2 & 0.2 & 22.6 & 0.2 & -0.4 & 0.8 \\
\hline PALA & 1760 & 7.07 & 9.897 & 45.602 & 238.747 & 16.3 & 0.4 & 20.2 & 0.4 & 2.2 & 1.5 \\
\hline PALZ & 2765 & 8.59 & 15.960 & 40.944 & 497.679 & 19.7 & 0.1 & 23.1 & 0.1 & 0.3 & 0.4 \\
\hline PAOL & 1835 & 5.58 & 14.568 & 41.031 & 714.571 & 17.5 & 0.4 & 21.2 & 0.7 & 0.2 & 1.1 \\
\hline PARM & 3036 & 8.76 & 10.312 & 44.765 & 121.827 & 17.9 & 0.2 & 21.7 & 0.2 & 0.7 & 0.6 \\
\hline PARO & 2234 & 7.28 & 8.081 & 44.446 & 849.772 & 15.9 & 0.2 & 21.1 & 0.2 & 0.6 & 0.5 \\
\hline PARR & 2122 & 6.54 & 11.123 & 45.777 & 875.755 & 16.8 & 0.3 & 20.8 & 0.3 & 0.1 & 1.0 \\
\hline PASS & 2117 & 6.25 & 11.902 & 46.193 & 1418.690 & 16.6 & 0.3 & 20.1 & 0.3 & 0.4 & 0.7 \\
\hline PAUN & 1180 & 3.55 & 13.349 & 38.106 & 113.504 & 20.5 & 0.4 & 21.9 & 0.5 & 1.1 & 1.3 \\
\hline PAZO & 2396 & 7.55 & 13.053 & 45.806 & 50.089 & 17.3 & 0.2 & 20.8 & 0.2 & 0.1 & 0.5 \\
\hline PBRA & 2531 & 9.07 & 14.229 & 42.124 & 571.948 & 19.6 & 0.3 & 22.7 & 0.3 & 0.0 & 0.9 \\
\hline PEJO & 2188 & 6.54 & 10.676 & 46.363 & 1612.677 & 15.7 & 0.4 & 21.0 & 0.3 & 0.9 & 0.9 \\
\hline PENC & 5020 & 14.54 & 19.282 & 47.790 & 291.737 & 14.7 & 0.1 & 22.0 & 0.1 & 0.0 & 0.4 \\
\hline PES2 & 1933 & 5.87 & 12.893 & 43.893 & 66.881 & 18.7 & 0.3 & 22.6 & 0.2 & 1.7 & 0.9 \\
\hline PESA & 805 & 3.52 & 12.918 & 43.901 & 59.296 & 19.3 & 0.3 & 22.9 & 0.4 & -0.1 & 1.2 \\
\hline PESC & 722 & 3.46 & 14.201 & 42.470 & 71.212 & 19.1 & 0.3 & 23.0 & 0.4 & -0.8 & 1.0 \\
\hline PESR & 1246 & 3.96 & 12.841 & 43.941 & 201.379 & 20.5 & 0.6 & 23.5 & 0.5 & -0.2 & 0.8 \\
\hline PFA2 & 2499 & 7.55 & 9.785 & 47.515 & 1090.095 & 16.0 & 0.2 & 20.2 & 0.2 & 0.8 & 0.8 \\
\hline PFER & 1323 & 4.54 & 10.295 & 42.793 & 71.979 & 16.7 & 0.8 & 21.0 & 0.7 & -0.7 & 2.1 \\
\hline PIAC & 2381 & 7.93 & 9.690 & 45.043 & 115.082 & 17.6 & 0.2 & 21.0 & 0.1 & 0.1 & 0.5 \\
\hline PIBI & 1146 & 3.39 & 12.453 & 43.128 & 258.961 & 16.8 & 0.4 & 20.8 & 0.5 & -0.4 & 1.4 \\
\hline PIC1 & 2406 & 7.55 & 9.690 & 45.043 & 115.304 & 17.5 & 0.2 & 20.9 & 0.2 & 1.5 & 0.6 \\
\hline PIET & 2821 & 9.05 & 12.402 & 43.451 & 745.467 & 17.9 & 0.1 & 21.6 & 0.1 & 1.0 & 0.3 \\
\hline PIGN & 1265 & 3.93 & 14.180 & 41.200 & 397.457 & 17.9 & 0.3 & 21.6 & 0.2 & -0.7 & 0.8 \\
\hline
\end{tabular}




\section{Continued}

\begin{tabular}{|c|c|c|c|c|c|c|c|c|c|c|c|}
\hline PILA & 1468 & 4.55 & 11.906 & 46.566 & 2141.701 & 15.8 & 0.6 & 20.6 & 0.5 & 1.1 & 1.4 \\
\hline PIOB & 870 & 3.52 & 12.482 & 43.612 & 448.001 & 18.9 & 0.5 & 22.9 & 0.4 & 0.7 & 1.3 \\
\hline PIPA & 2570 & 8.25 & 16.816 & 39.485 & 478.963 & 18.8 & 0.1 & 24.0 & 0.1 & 1.2 & 0.4 \\
\hline PITI & 1720 & 5.50 & 11.673 & 42.634 & 392.020 & 16.7 & 0.4 & 20.9 & 0.4 & 0.3 & 1.0 \\
\hline PLAC & 3045 & 9.84 & 16.438 & 38.449 & 594.660 & 18.4 & 0.1 & 24.1 & 0.1 & 1.1 & 0.4 \\
\hline POFI & 2740 & 8.31 & 13.712 & 41.717 & 850.419 & 17.0 & 0.3 & 21.5 & 0.2 & 1.6 & 0.7 \\
\hline POGG & 2650 & 8.15 & 16.254 & 40.917 & 520.863 & 19.1 & 0.3 & 23.4 & 0.3 & 0.4 & 1.0 \\
\hline PORD & 2397 & 6.94 & 12.661 & 45.957 & 81.764 & 17.0 & 0.4 & 20.5 & 0.2 & -0.1 & 0.8 \\
\hline POZL & 1129 & 3.51 & 14.794 & 36.729 & 90.654 & 20.5 & 0.4 & 21.6 & 0.4 & 0.2 & 1.1 \\
\hline POZZ & 2186 & 6.55 & 11.682 & 46.423 & 1392.505 & 16.5 & 0.2 & 20.7 & 0.2 & 0.8 & 0.7 \\
\hline PRAI & 820 & 2.99 & 15.780 & 39.897 & 59.793 & 18.3 & 0.6 & 19.8 & 0.8 & 0.7 & 1.9 \\
\hline PRAT & 4630 & 14.55 & 11.099 & 43.886 & 119.966 & 17.3 & 0.1 & 21.4 & 0.1 & 0.1 & 0.1 \\
\hline PREM & 1964 & 6.76 & 9.878 & 45.870 & 671.999 & 16.1 & 0.3 & 20.5 & 0.2 & 0.7 & 0.7 \\
\hline PRET & 1489 & 4.55 & 12.073 & 47.029 & 1912.767 & 15.2 & 0.7 & 21.7 & 0.5 & 0.1 & 1.3 \\
\hline PRIG & 1096 & 4.54 & 15.109 & 40.312 & 134.092 & 17.9 & 1.0 & 21.6 & 0.8 & -0.7 & 3.2 \\
\hline PRTG & 3032 & 6.94 & 12.833 & 45.767 & 59.527 & 18.2 & 0.3 & 21.1 & 0.3 & -2.3 & 4.3 \\
\hline PSAN & 1736 & 6.61 & 14.139 & 42.519 & 62.214 & 18.3 & 0.2 & 23.1 & 0.2 & -1.3 & 0.7 \\
\hline PSB1 & 2831 & 9.31 & 14.811 & 41.223 & 588.324 & 18.1 & 0.1 & 22.3 & 0.1 & 0.5 & 0.4 \\
\hline PSST & 798 & 3.52 & 11.120 & 42.428 & 72.275 & 16.8 & 0.5 & 20.9 & 0.4 & -2.3 & 1.4 \\
\hline PSTE & 2050 & 7.55 & 11.120 & 42.428 & 72.366 & 16.4 & 0.3 & 21.1 & 0.2 & -0.3 & 0.8 \\
\hline PTNZ & 1296 & 4.13 & 15.817 & 40.635 & 731.144 & 20.2 & 0.5 & 23.6 & 0.5 & 0.3 & 1.4 \\
\hline PTO1 & 1728 & 4.99 & 12.334 & 44.952 & 49.312 & 17.0 & 0.2 & 21.1 & 0.2 & -4.8 & 0.6 \\
\hline PTRJ & 2500 & 9.00 & 14.529 & 41.364 & 1113.089 & 17.5 & 0.2 & 22.9 & 0.2 & 0.9 & 0.5 \\
\hline PTRP & 2347 & 8.04 & 16.061 & 40.532 & 828.710 & 19.2 & 0.2 & 23.7 & 0.2 & 1.1 & 0.5 \\
\hline RAFF & 2535 & 9.52 & 14.362 & 37.223 & 300.671 & 20.2 & 0.1 & 21.0 & 0.1 & -0.6 & 0.3 \\
\hline RAMS & 1742 & 5.38 & 10.278 & 44.411 & 851.642 & 17.6 & 0.4 & 21.7 & 0.2 & 0.2 & 0.7 \\
\hline RAPA & 738 & 3.41 & 9.221 & 44.355 & 70.378 & 15.7 & 0.5 & 21.6 & 0.5 & -0.3 & 1.3 \\
\hline RASS & 2882 & 9.22 & 11.836 & 43.647 & 354.035 & 17.5 & 0.2 & 20.9 & 0.1 & 0.3 & 0.5 \\
\hline RAVE & 2941 & 10.12 & 12.200 & 44.413 & 54.814 & 18.6 & 0.1 & 23.0 & 0.1 & -3.9 & 0.2 \\
\hline RAVS & 2475 & 8.44 & 12.192 & 44.405 & 51.801 & 18.5 & 0.3 & 22.9 & 0.2 & -4.0 & 0.7 \\
\hline RDPI & 2439 & 8.85 & 12.710 & 41.760 & 816.706 & 17.6 & 0.3 & 20.9 & 0.4 & 2.5 & 0.8 \\
\hline RE01 & 2280 & 9.22 & 10.640 & 44.887 & 69.778 & 16.4 & 0.1 & 22.3 & 0.1 & -2.7 & 0.5 \\
\hline REBO & 1435 & 5.16 & 12.030 & 45.196 & 58.199 & 17.0 & 0.2 & 21.1 & 0.2 & -1.6 & 0.6 \\
\hline REGG & 2174 & 7.29 & 10.637 & 44.706 & 103.569 & 18.1 & 0.2 & 23.3 & 0.2 & -1.6 & 0.5 \\
\hline RESU & 2090 & 7.35 & 14.057 & 37.647 & 782.470 & 18.0 & 0.2 & 22.2 & 0.2 & 0.8 & 0.6 \\
\hline RIET & 2525 & 7.55 & 12.857 & 42.408 & 457.221 & 17.0 & 0.2 & 20.9 & 0.3 & 0.8 & 0.8 \\
\hline
\end{tabular}




\section{Continued}

\begin{tabular}{|c|c|c|c|c|c|c|c|c|c|c|c|}
\hline RMPO & 3043 & 9.07 & 12.703 & 41.811 & 449.666 & 17.5 & 0.2 & 21.3 & 0.2 & 0.3 & 0.5 \\
\hline RNI2 & 3700 & 10.94 & 14.152 & 41.704 & 1017.953 & 18.4 & 0.2 & 22.3 & 0.2 & 1.0 & 0.5 \\
\hline ROGA & 3825 & 11.89 & 10.340 & 44.207 & 1311.571 & 16.6 & 0.1 & 20.8 & 0.1 & -0.7 & 0.2 \\
\hline RONC & 2210 & 6.55 & 10.670 & 45.984 & 885.439 & 16.4 & 0.2 & 20.3 & 0.2 & 0.5 & 0.7 \\
\hline ROPI & 2168 & 6.28 & 13.337 & 42.332 & 991.841 & 17.3 & 0.5 & 21.8 & 0.5 & -2.1 & 0.8 \\
\hline ROSS & 978 & 3.08 & 16.641 & 39.600 & 96.204 & 20.6 & 0.6 & 24.6 & 0.6 & -0.2 & 1.6 \\
\hline ROVE & 3189 & 9.38 & 11.042 & 45.894 & 261.771 & 17.3 & 0.1 & 20.7 & 0.1 & 0.9 & 0.5 \\
\hline ROVI & 2247 & 6.90 & 11.783 & 45.087 & 62.783 & 18.0 & 0.2 & 21.4 & 0.2 & -0.7 & 0.5 \\
\hline ROVR & 2165 & 6.77 & 11.072 & 45.647 & 1365.924 & 17.1 & 0.2 & 21.3 & 0.2 & 0.6 & 0.5 \\
\hline RSMN & 3179 & 9.64 & 12.451 & 43.934 & 767.430 & 19.2 & 0.2 & 23.3 & 0.1 & -0.3 & 0.5 \\
\hline RSPX & 3025 & 9.17 & 7.265 & 45.148 & 1323.230 & 15.8 & 0.1 & 20.7 & 0.1 & 0.9 & 0.4 \\
\hline RSTO & 4003 & 12.55 & 14.002 & 42.658 & 102.583 & 18.8 & 0.2 & 23.2 & 0.2 & -0.5 & 0.4 \\
\hline SABA & 928 & 3.86 & 19.697 & 44.760 & 140.883 & 14.6 & 0.3 & 24.0 & 0.4 & 1.7 & 0.9 \\
\hline SACR & 3126 & 10.54 & 14.706 & 41.398 & 847.043 & 17.6 & 0.2 & 21.6 & 0.2 & 1.8 & 0.3 \\
\hline SALA & 1690 & 5.54 & 15.557 & 40.417 & 504.518 & 18.3 & 0.3 & 23.2 & 0.5 & 1.0 & 1.1 \\
\hline SALB & 1947 & 6.05 & 16.346 & 39.877 & 1187.635 & 20.0 & 0.3 & 24.0 & 0.3 & 1.1 & 0.7 \\
\hline SALO & 3166 & 9.69 & 10.524 & 45.618 & 589.067 & 15.9 & 0.2 & 21.1 & 0.2 & -0.9 & 0.6 \\
\hline SAPP & 1955 & 6.41 & 12.690 & 46.567 & 1329.481 & 16.6 & 0.2 & 20.8 & 0.2 & 2.1 & 0.7 \\
\hline SAPR & 1849 & 7.32 & 15.630 & 40.074 & 65.370 & 17.7 & 0.2 & 21.8 & 0.2 & -0.4 & 0.8 \\
\hline SAQU & 2029 & 6.18 & 8.399 & 44.292 & 118.029 & 16.0 & 0.4 & 20.7 & 0.4 & -1.3 & 1.0 \\
\hline SARN & 2202 & 6.54 & 11.142 & 46.419 & 1049.694 & 16.5 & 0.2 & 20.7 & 0.2 & 0.8 & 0.6 \\
\hline SASA & 2532 & 8.17 & 17.965 & 40.385 & 99.264 & 18.5 & 0.3 & 23.8 & 0.3 & -0.8 & 1.0 \\
\hline SASO & 1077 & 4.94 & 11.822 & 43.928 & 824.938 & 20.2 & 1.0 & 23.3 & 0.9 & -0.7 & 3.1 \\
\hline SASS & 1964 & 7.55 & 8.567 & 40.721 & 302.460 & 16.4 & 0.3 & 21.3 & 0.3 & 2.2 & 0.9 \\
\hline SAVI & 1685 & 5.29 & 7.661 & 44.648 & 380.441 & 16.2 & 0.2 & 20.5 & 0.2 & -0.7 & 0.7 \\
\hline SBG2 & 2574 & 7.46 & 13.110 & 47.803 & 1323.363 & 15.9 & 0.2 & 20.7 & 0.2 & 1.2 & 0.7 \\
\hline SBPO & 3081 & 9.15 & 10.920 & 45.051 & 62.434 & 17.0 & 0.1 & 20.8 & 0.1 & 0.3 & 0.4 \\
\hline SCHI & 2357 & 7.15 & 11.363 & 45.718 & 254.628 & 16.9 & 0.2 & 20.8 & 0.2 & 0.2 & 0.9 \\
\hline SCHR & 2431 & 9.84 & 16.085 & 40.190 & 859.448 & 19.2 & 0.1 & 23.6 & 0.1 & 1.3 & 0.4 \\
\hline SCRA & 2593 & 8.65 & 14.002 & 42.268 & 166.548 & 20.3 & 0.2 & 22.6 & 0.2 & -0.3 & 0.7 \\
\hline SCTE & 2725 & 9.45 & 18.467 & 40.072 & 143.208 & 18.8 & 0.1 & 23.7 & 0.1 & -0.1 & 0.3 \\
\hline SDNA & 2207 & 6.90 & 12.564 & 45.630 & 66.745 & 17.4 & 0.2 & 21.0 & 0.2 & -1.8 & 0.5 \\
\hline SEAN & 699 & 3.42 & 11.026 & 43.831 & 94.301 & 17.5 & 1.0 & 21.8 & 0.7 & -2.1 & 2.2 \\
\hline SENI & 797 & 3.52 & 13.215 & 43.708 & 65.047 & 19.0 & 0.3 & 23.0 & 0.3 & 0.2 & 1.0 \\
\hline SERM & 2501 & 7.55 & 11.300 & 45.007 & 67.995 & 17.5 & 0.2 & 22.4 & 0.2 & 0.2 & 0.5 \\
\hline SERR & 1518 & 4.40 & 8.853 & 44.731 & 251.173 & 16.7 & 0.2 & 21.0 & 0.2 & 0.1 & 0.7 \\
\hline
\end{tabular}




\section{Continued}

\begin{tabular}{|c|c|c|c|c|c|c|c|c|c|c|c|}
\hline SERS & 2802 & 8.84 & 16.689 & 39.036 & 1214.970 & 18.5 & 0.1 & 24.5 & 0.1 & 0.7 & 0.4 \\
\hline SEVI & 1701 & 5.18 & 7.837 & 45.535 & 323.494 & 15.4 & 0.3 & 20.2 & 0.3 & 1.2 & 1.0 \\
\hline SGIO & 809 & 3.52 & 11.802 & 45.601 & 91.982 & 16.7 & 0.5 & 20.4 & 0.5 & -0.5 & 1.6 \\
\hline SGIP & 3401 & 10.36 & 11.183 & 44.636 & 63.496 & 17.7 & 0.2 & 22.7 & 0.2 & -5.4 & 0.4 \\
\hline SGL1 & 1960 & 6.03 & 13.766 & 41.407 & 100.679 & 17.0 & 0.4 & 22.3 & 0.4 & 3.7 & 1.8 \\
\hline SGRE & 1968 & 6.18 & 13.501 & 42.336 & 808.381 & 17.9 & 0.5 & 20.9 & 0.4 & -2.5 & 1.2 \\
\hline SGRT & 2884 & 9.15 & 15.744 & 41.755 & 949.239 & 20.0 & 0.2 & 23.7 & 0.1 & 0.7 & 0.4 \\
\hline SGTA & 3032 & 9.49 & 15.365 & 41.136 & 716.892 & 19.5 & 0.1 & 23.0 & 0.1 & 1.0 & 0.3 \\
\hline SIEN & 3120 & 11.60 & 11.338 & 43.315 & 386.652 & 16.8 & 0.1 & 20.8 & 0.1 & 0.5 & 0.3 \\
\hline SILA & 860 & 3.52 & 10.785 & 46.625 & 753.937 & 16.0 & 1.9 & 21.5 & 1.3 & 2.1 & 6.7 \\
\hline SIN2 & 1725 & 5.62 & 9.692 & 40.574 & 104.334 & 16.5 & 0.4 & 21.8 & 0.5 & 0.2 & 1.1 \\
\hline SIRC & 1920 & 5.64 & 15.282 & 37.076 & 90.443 & 20.2 & 0.2 & 21.8 & 0.2 & -1.9 & 0.7 \\
\hline SIRI & 2706 & 8.59 & 15.866 & 40.184 & 1144.171 & 19.6 & 0.1 & 24.1 & 0.2 & -0.4 & 0.4 \\
\hline SLCN & 2712 & 10.13 & 15.633 & 40.391 & 1048.759 & 18.1 & 0.1 & 23.2 & 0.1 & 0.8 & 0.4 \\
\hline SMRA & 2596 & 9.07 & 13.924 & 42.048 & 474.097 & 19.5 & 0.3 & 23.0 & 0.2 & -2.4 & 1.0 \\
\hline SNAL & 3215 & 10.55 & 15.209 & 40.926 & 865.647 & 18.0 & 0.1 & 22.4 & 0.1 & 1.2 & 0.3 \\
\hline SOFI & 4478 & 14.36 & 23.395 & 42.556 & 1119.535 & 11.9 & 0.1 & 23.6 & 0.2 & 0.0 & 0.5 \\
\hline SONA & 816 & 3.52 & 10.828 & 45.445 & 180.903 & 17.0 & 0.5 & 21.2 & 0.4 & -1.8 & 1.6 \\
\hline SORR & 1350 & 4.00 & 14.396 & 40.629 & 131.733 & 17.6 & 0.7 & 21.9 & 0.8 & 0.5 & 1.6 \\
\hline SOV1 & 1273 & 4.10 & 16.547 & 38.684 & 61.634 & 18.3 & 0.3 & 24.5 & 0.4 & 0.6 & 1.1 \\
\hline SPCI & 2716 & 8.19 & 15.260 & 41.740 & 244.448 & 18.4 & 0.3 & 23.5 & 0.3 & 1.0 & 1.0 \\
\hline SPER & 2122 & 6.55 & 11.509 & 46.069 & 604.829 & 16.6 & 0.2 & 20.6 & 0.2 & 0.5 & 0.6 \\
\hline SPRN & 2653 & 7.55 & 16.583 & 47.684 & 278.854 & 15.8 & 0.2 & 22.3 & 0.2 & -0.6 & 0.6 \\
\hline STBZ & 1455 & 4.55 & 11.426 & 46.898 & 1043.752 & 16.0 & 0.2 & 21.0 & 0.2 & 2.2 & 0.9 \\
\hline SUSE & 1031 & 4.08 & 12.209 & 45.857 & 221.733 & 17.7 & 0.5 & 20.6 & 0.5 & -0.9 & 2.9 \\
\hline SVTO & 2786 & 8.59 & 16.441 & 40.604 & 493.614 & 19.4 & 0.1 & 23.3 & 0.1 & 0.6 & 0.3 \\
\hline TAMB & 1205 & 3.87 & 12.396 & 46.061 & 1117.585 & 15.8 & 0.4 & 21.4 & 0.4 & 0.9 & 1.1 \\
\hline TAOR & 2210 & 7.05 & 15.289 & 37.853 & 250.563 & 19.7 & 0.4 & 21.1 & 0.4 & 0.7 & 1.0 \\
\hline TARA & 1454 & 4.57 & 17.284 & 40.527 & 126.559 & 20.0 & 0.3 & 23.4 & 0.2 & -0.4 & 0.8 \\
\hline TARO & 2472 & 8.00 & 9.766 & 44.488 & 473.618 & 17.1 & 0.2 & 21.5 & 0.3 & 0.6 & 0.9 \\
\hline TARQ & 1773 & 5.38 & 11.758 & 42.254 & 185.665 & 16.4 & 0.5 & 20.7 & 0.5 & 1.3 & 1.9 \\
\hline TARV & 2357 & 6.94 & 13.593 & 46.502 & 761.144 & 17.0 & 0.3 & 21.2 & 0.2 & 2.3 & 1.0 \\
\hline TELI & 829 & 3.47 & 15.010 & 41.972 & 62.303 & 18.0 & 0.6 & 25.5 & 0.6 & -9.5 & 1.6 \\
\hline TEMP & 2234 & 7.05 & 9.100 & 40.908 & 597.268 & 16.6 & 0.2 & 21.8 & 0.2 & 1.0 & 0.7 \\
\hline TEOL & 3371 & 10.27 & 11.677 & 45.343 & 203.405 & 17.9 & 0.2 & 20.8 & 0.2 & 0.1 & 0.5 \\
\hline TERA & 1778 & 6.48 & 13.700 & 42.662 & 333.339 & 20.6 & 0.4 & 23.6 & 0.4 & -1.5 & 1.3 \\
\hline
\end{tabular}




\section{Continued}

\begin{tabular}{|c|c|c|c|c|c|c|c|c|c|c|c|}
\hline TERI & 2010 & 7.46 & 12.650 & 42.567 & 209.799 & 17.5 & 0.4 & 20.1 & 0.5 & 0.1 & 1.2 \\
\hline TGPO & 2178 & 6.89 & 12.228 & 45.003 & 49.355 & 17.4 & 0.2 & 21.3 & 0.2 & -5.1 & 0.6 \\
\hline TGRC & 937 & 3.08 & 15.651 & 38.108 & 139.230 & 19.4 & 0.6 & 23.4 & 0.6 & 1.7 & 1.8 \\
\hline TITO & 2225 & 6.54 & 15.724 & 40.601 & 818.203 & 19.0 & 0.3 & 23.3 & 0.3 & 0.4 & 0.7 \\
\hline TLSE & 4945 & 14.53 & 1.481 & 43.561 & 207.186 & 16.3 & 0.1 & 19.5 & 0.1 & 0.5 & 0.4 \\
\hline TOIR & 1874 & 5.78 & 8.212 & 44.124 & 106.636 & 16.2 & 0.3 & 21.1 & 0.2 & -1.6 & 1.1 \\
\hline TOLF & 3226 & 10.34 & 12.000 & 42.064 & 362.759 & 17.1 & 0.1 & 20.7 & 0.2 & -0.4 & 0.4 \\
\hline TORC & 823 & 3.52 & 7.641 & 45.017 & 301.121 & 16.0 & 0.4 & 20.9 & 0.4 & 1.5 & 1.1 \\
\hline TORI & 4800 & 14.55 & 7.661 & 45.063 & 310.746 & 15.9 & 0.1 & 20.1 & 0.1 & 0.6 & 0.2 \\
\hline TREB & 996 & 3.08 & 16.527 & 39.869 & 138.358 & 20.0 & 0.6 & 24.0 & 0.6 & 2.0 & 1.6 \\
\hline TREC & 3500 & 11.70 & 10.018 & 44.337 & 490.707 & 16.8 & 0.2 & 20.8 & 0.2 & -0.3 & 0.5 \\
\hline TREN & 2090 & 6.54 & 11.118 & 46.091 & 275.298 & 16.4 & 0.2 & 21.1 & 0.2 & -0.2 & 0.7 \\
\hline TREV & 2025 & 6.28 & 12.222 & 45.680 & 78.194 & 17.2 & 0.2 & 20.9 & 0.2 & -0.2 & 0.5 \\
\hline TRIO & 2183 & 6.94 & 13.788 & 45.661 & 161.608 & 17.9 & 0.2 & 20.9 & 0.3 & 0.5 & 0.7 \\
\hline TRIE & 4183 & 12.44 & 13.764 & 45.710 & 323.409 & 17.8 & 0.1 & 20.3 & 0.1 & 0.2 & 0.3 \\
\hline TRIV & 3321 & 10.35 & 14.550 & 41.767 & 599.357 & 18.9 & 0.1 & 23.7 & 0.1 & 0.6 & 0.3 \\
\hline TRLU & 3826 & 12.30 & 11.267 & 43.609 & 461.460 & 17.4 & 0.1 & 21.6 & 0.1 & 0.2 & 0.1 \\
\hline UDI1 & 3055 & 9.19 & 13.253 & 46.038 & 149.175 & 17.7 & 0.1 & 20.8 & 0.1 & 0.0 & 0.2 \\
\hline UDIN & 2124 & 6.94 & 13.228 & 46.055 & 180.643 & 17.5 & 0.2 & 20.8 & 0.3 & -0.1 & 0.8 \\
\hline UGEN & 2757 & 8.18 & 18.162 & 39.928 & 152.185 & 18.6 & 0.3 & 23.8 & 0.2 & 0.2 & 0.9 \\
\hline UMBE & 2887 & 9.67 & 12.329 & 43.311 & 305.639 & 17.4 & 0.1 & 21.4 & 0.1 & 2.8 & 0.4 \\
\hline UNPA & 1022 & 3.28 & 13.348 & 38.106 & 103.371 & 19.7 & 0.6 & 22.0 & 0.7 & 2.3 & 1.8 \\
\hline UNPG & 4719 & 14.55 & 12.356 & 43.119 & 351.097 & 17.2 & 0.1 & 21.0 & 0.2 & -0.4 & 0.4 \\
\hline UNTR & 2687 & 10.53 & 12.674 & 42.559 & 219.147 & 17.6 & 0.5 & 20.6 & 0.4 & -0.3 & 0.9 \\
\hline USAL & 1897 & 5.39 & 18.112 & 40.335 & 69.194 & 19.1 & 0.2 & 23.9 & 0.2 & -0.5 & 0.6 \\
\hline VAGA & 2922 & 9.35 & 14.234 & 41.415 & 784.814 & 16.1 & 0.4 & 21.0 & 0.2 & 0.7 & 0.4 \\
\hline VALC & 2583 & 8.29 & 12.285 & 43.279 & 663.122 & 17.5 & 0.1 & 21.2 & 0.2 & 0.6 & 0.4 \\
\hline VALD & 1296 & 4.25 & 11.998 & 45.898 & 299.100 & 16.0 & 0.4 & 21.4 & 0.4 & -1.2 & 0.8 \\
\hline VALE & 2751 & 8.00 & 16.905 & 41.016 & 207.261 & 18.8 & 0.3 & 23.5 & 0.2 & 0.4 & 0.8 \\
\hline VARE & 1515 & 4.88 & 8.829 & 45.814 & 443.103 & 16.0 & 0.2 & 20.5 & 0.2 & 0.4 & 0.8 \\
\hline VELO & 1943 & 6.19 & 11.367 & 45.789 & 405.238 & 16.1 & 0.2 & 20.9 & 0.2 & -1.0 & 0.8 \\
\hline VEN1 & 2268 & 7.07 & 12.354 & 45.431 & 60.434 & 15.9 & 0.2 & 21.2 & 0.2 & -1.9 & 0.5 \\
\hline VENO & 1724 & 5.26 & 15.809 & 40.967 & 467.786 & 19.8 & 0.4 & 23.6 & 0.3 & -0.1 & 0.8 \\
\hline VENT & 3204 & 9.46 & 13.422 & 40.795 & 112.550 & 17.2 & 0.1 & 21.2 & 0.1 & -0.9 & 0.3 \\
\hline VERB & 807 & 3.52 & 8.567 & 45.941 & 282.232 & 15.9 & 0.4 & 20.3 & 0.4 & 2.7 & 1.4 \\
\hline VERG & 2583 & 7.86 & 11.111 & 44.287 & 271.953 & 17.4 & 0.2 & 23.3 & 0.2 & 1.0 & 0.5 \\
\hline
\end{tabular}




\begin{tabular}{|c|c|c|c|c|c|c|c|c|c|c|c|}
\hline \multicolumn{12}{|c|}{ Continued } \\
\hline VERL & 1745 & 5.28 & 8.421 & 45.331 & 183.933 & 16.1 & 0.2 & 20.6 & 0.3 & -1.0 & 1.0 \\
\hline VERO & 2465 & 7.55 & 11.002 & 45.445 & 123.795 & 16.0 & 0.4 & 20.9 & 0.4 & 0.8 & 1.1 \\
\hline VGAR & 1465 & 4.46 & 15.962 & 41.893 & 514.121 & 19.4 & 0.3 & 23.5 & 0.2 & -0.8 & 1.0 \\
\hline VICE & 2163 & 6.90 & 11.556 & 45.564 & 96.172 & 16.8 & 0.2 & 20.8 & 0.2 & -0.9 & 0.6 \\
\hline VIGG & 1155 & 3.84 & 16.116 & 39.986 & 954.632 & 19.1 & 0.7 & 24.0 & 0.8 & 1.9 & 1.6 \\
\hline VILL & 4993 & 14.55 & 356.048 & 40.444 & 647.348 & 16.4 & 0.2 & 19.2 & 0.2 & 0.5 & 0.5 \\
\hline VILS & 1652 & 7.24 & 9.521 & 39.143 & 101.727 & 16.9 & 0.4 & 22.0 & 0.6 & 0.0 & 1.3 \\
\hline VINC & 640 & 3.47 & 14.562 & 41.468 & 571.570 & 18.4 & 0.7 & 23.4 & 0.5 & -0.1 & 1.6 \\
\hline VIT1 & 1743 & 5.38 & 12.103 & 42.426 & 405.640 & 16.8 & 0.2 & 21.1 & 0.2 & 0.8 & 0.7 \\
\hline VITE & 719 & 3.52 & 12.112 & 42.419 & 418.740 & 16.6 & 0.4 & 20.3 & 0.4 & 0.1 & 1.2 \\
\hline VITT & 1168 & 3.40 & 12.301 & 45.993 & 194.645 & 17.0 & 0.5 & 21.4 & 0.4 & -0.1 & 1.1 \\
\hline VLPN & 766 & 3.52 & 10.852 & 43.006 & 207.284 & 16.9 & 0.3 & 21.3 & 0.3 & 0.3 & 1.0 \\
\hline VLSG & 2661 & 9.54 & 15.642 & 38.224 & 117.389 & 18.5 & 0.2 & 23.2 & 0.1 & 0.5 & 0.3 \\
\hline VMIG & 1011 & 3.12 & 7.651 & 43.786 & 70.322 & 15.9 & 0.7 & 20.2 & 1.0 & 0.0 & 1.4 \\
\hline VR02 & 2033 & 7.14 & 10.994 & 45.438 & 127.491 & 16.4 & 0.3 & 21.1 & 0.2 & 1.3 & 0.8 \\
\hline VRRA & 1983 & 6.11 & 10.865 & 43.401 & 597.854 & 16.7 & 0.3 & 21.9 & 0.3 & 0.5 & 1.1 \\
\hline VTRA & 2673 & 9.05 & 14.708 & 42.110 & 209.780 & 18.3 & 0.2 & 22.8 & 0.2 & -1.0 & 0.7 \\
\hline VULT & 2736 & 9.91 & 15.616 & 40.955 & 1082.214 & 19.6 & 0.1 & 23.4 & 0.1 & 0.6 & 0.3 \\
\hline VVLO & 4506 & 14.54 & 13.623 & 41.870 & 1045.769 & 18.0 & 0.2 & 21.6 & 0.2 & 1.4 & 0.7 \\
\hline WTZR & 5118 & 14.54 & 12.879 & 49.144 & 666.028 & 15.3 & 0.2 & 20.4 & 0.2 & 0.6 & 0.5 \\
\hline ZAGA & 984 & 3.52 & 12.748 & 41.862 & 198.420 & 17.3 & 0.4 & 21.0 & 0.5 & -0.3 & 1.1 \\
\hline ZERI & 2573 & 9.48 & 9.752 & 44.388 & 1448.007 & 16.3 & 0.2 & 21.1 & 0.1 & -0.5 & 0.4 \\
\hline ZOUF & 3923 & 12.18 & 12.974 & 46.557 & 1946.492 & 16.4 & 0.1 & 21.0 & 0.1 & 2.0 & 0.2 \\
\hline
\end{tabular}

